\title{
Phosphorus-Bearing Sulfides and Their Associations in CM Chondrites
}

\author{
M. A. Nazarov ${ }^{a}$, G. Kurat ${ }^{b, c}$, F. Brandstaetter ${ }^{c}$, T. Ntaflos ${ }^{b}$, \\ M. Chaussidon ${ }^{d}$, and P. Hoppe ${ }^{e}$ \\ ${ }^{a}$ Vernadsky Institute of Geochemistry and Analytical Chemistry, Russian Academy of Sciences, \\ ul. Kosygina 19, Moscow, 119991 Russia \\ e-mail:nazarov@geokhi.ru \\ ${ }^{b}$ Departament für Lithosphärenforschung, Universität Wien, Althanstrasse 14, 1090 Wien, Austria \\ e-mail: gero.kurat@univie.ac.at; theodoros.ntaflos@univie.ac.at \\ ${ }^{c}$ Naturhistorisches Museum, Burgring 7, A-1014 Wien, Austria \\ e-mail: franz.brandstaetter@nhm-wien.ac.at \\ ${ }^{d}$ CRPG-CNRS, BP20, F-54501 Vandoeuvre-les-Nancy, France \\ e-mail: chocho@crpg.cnrs-nancy.fr \\ ${ }^{e}$ Max-Planck-Institut für Chemie, Postfach 3060, D-55022 Mainz, Germany \\ e-mail: hoppe@mpch-mainz.mpg.de \\ Received June 11, 2008
}

\begin{abstract}
Phosphorus-bearing Fe and Ni sulfides represent a new type of phosphorus compounds and are characteristic accessory phases of CM chondrites. The proportions of atoms in the sulfides can be approximated by the equation $(\mathrm{Fe}+\mathrm{Ni}) / \mathrm{P}=0.965 \pm 0.003(1 \sigma) \cdot \mathrm{S} / \mathrm{P}+1.255 \pm 0.036(1 \sigma)$. Sulfides with high $\mathrm{S} / \mathrm{P}$ ratios are systematically richer in Fe and poorer in Ni compared with low-S/P sulfides. Their characteristic minor elements are $\mathrm{Cr}, \mathrm{Ca}, \mathrm{Co}, \mathrm{K}$, and $\mathrm{Na}$. The contents of $\mathrm{Cr}$ and $\mathrm{Ca}$ may reach several weight percent, but their incorporation does not affect the relation between $(\mathrm{Fe}+\mathrm{Ni}) / \mathrm{P}$ and $\mathrm{S} / \mathrm{P}$. This is also true of light elements $(\mathrm{O}$ and $\mathrm{H})$, which probably occur in the P-bearing sulfides in certain amounts. The sulfides are usually associated with schreibersite, barringerite, eskolaite, and daubreelite. A negative correlation was observed between the Fe/Ni ratios of coexisting P-bearing sulfides and phosphides. Metallic iron was never found in association with the sulfides. It can be suggested that P-bearing sulfide is a primary phase rather than a secondary alteration product formed under the conditions of the CM chondrite parent body. This phase had to be stable in the solar nebula after the formation of $\mathrm{Ca}-\mathrm{Al}$ inclusions and before the condensation of $\mathrm{Fe}-\mathrm{Ni}$ metal. At high temperatures, $\mathrm{P}$-bearing sulfide with low $\mathrm{Fe} / \mathrm{Ni}$ and $\mathrm{S} / \mathrm{P}$ ratios coexists with schreibersite in the solar gas. During condensation schreibersite is replaced by barringerite, which is accompanied by a decrease in the Fe/Ni ratio of phosphides and an increase in the $\mathrm{S} / \mathrm{P}$ and Fe/Ni ratios of P-bearing sulfides. Trace element data suggest that the P-bearing sulfides could be formed in the solar nebula by the sulfidization of a precursor phase of extrasolar origin.
\end{abstract}

DOI: $10.1134 / \mathrm{S} 0869591109020015$

\section{INTRODUCTION}

A peculiar $\mathrm{Fe}-\mathrm{Ni}-\mathrm{Cr}$ sulfide containing phosphorus was first described by Bunch at al. (1979) and Bunch and Chang (1980) in the Murchison and Murray CM chondrites and in carbonaceous chondrite clasts from the Jodzie howardite. These authors supposed that this sulfide could be the hypothetical Q-phase that was considered as the main carrier of fission xenon, which formed by the decay of an extinct superheavy element (Lewis et al., 1975). Subsequently, a similar Cr-poor sulfide was found by Nazarov et al. (1993) in a carbonaceous chondrite clast from the Erevan howardite. The existence of such a phase was intriguing, because $P$ was never detected in terrestrial and extraterrestrial sulfides. Phosphorus shows siderophile properties under reducing conditions, and theoretical calculations of the con- densation of solar gas (Grossman and Olsen, 1974; Wai and Wasson, 1977; Fegley and Lewis, 1980) showed that $\mathrm{P}$ should dissolve in $\mathrm{Fe}-\mathrm{Ni}$ metal or condense as schreibersite, $\left((\mathrm{Fe}, \mathrm{Ni})_{3} \mathrm{P}\right)$. Under oxidizing conditions, $\mathrm{P}$ is a typical lithophile element, which behaves incompatibly during magmatic fractionation. This unusual case of the chalcophile behavior of $\mathrm{P}$ motivated our detailed study of the conditions of occurrence and the chemistry of P-bearing sulfides in CM and some other chondrites. At the beginning of this project, we thought that this phase is a mineralogical oddity and we would never obtain sufficient data for the understanding of its chemical structure and origin. But surprisingly, rare grains of P-bearing sulfides were found in almost all of the CM chondrites studied by us, and we have learned much more on the nature of this phase than could have been expected. This paper is aimed at summarizing the 
Table 1. Abundances of P-rich opaque phases in CM chondrites

\begin{tabular}{|c|c|c|c|c|c|c|c|c|c|}
\hline \multirow[b]{2}{*}{ Meteorite } & \multirow[b]{2}{*}{ Collection } & \multirow{2}{*}{$\begin{array}{l}\text { Area of thin } \\
\text { sections stud- } \\
\text { ied, } \mathrm{cm}^{2}\end{array}$} & \multicolumn{5}{|c|}{ Number of grains of P-rich phases } & \multirow{2}{*}{$\begin{array}{c}\text { Content, } \\
\text { ppm }\end{array}$} & \multirow{2}{*}{$\begin{array}{c}P n /(P n+P o) \\
\%\end{array}$} \\
\hline & & & P-sulfide & $\begin{array}{l}\text { Cr, P-sul- } \\
\text { fide }\end{array}$ & Barringerite & $\begin{array}{c}\text { Schreiber- } \\
\text { site }\end{array}$ & Total & & \\
\hline Acfer 094 & NHM & 1.62 & n.d. & n.d. & n.d. & n.d. & n.d. & n.d. & n.m. \\
\hline ALH 83100 & NASA & 0.854 & 45 & 4 & 3 & 1 & 53 & 50 & 86.3 \\
\hline ALH 83102 & NASA & 0.844 & 36 & 1 & 3 & n.d. & 40 & 38 & 83.0 \\
\hline ALH 84029 & NASA & 0.995 & 76 & n.d & 4 & n.d. & 80 & 64 & 86.0 \\
\hline ALH 84044 & NASA & 0.359 & 21 & 3 & 4 & 1 & 29 & 65 & 92.9 \\
\hline ALH 85013 & NASA & 0.431 & 24 & 5 & 3 & 1 & 33 & 61 & 61.5 \\
\hline Banten & AMNH & 1.054 & 40 & 15 & n.d. & 8 & 63 & 48 & 33.8 \\
\hline Bells & AMNH & $\sim 1$ & 1 & n.d. & n.d. & n.d. & 1 & $<1$ & n.m. \\
\hline Boriskino & RAS & 2.698 & 84 & 14 & 10 & 2 & 110 & 33 & 39.6 \\
\hline Cochabamba & NHM & 1.142 & 66 & 46 & 42 & 1 & 155 & 109 & 1.4 \\
\hline Cold Bokkeveld & NHM, RAS & 4.770 & 63 & 35 & 5 & 2 & 105 & 18 & 67.2 \\
\hline Dhofar 225 & RAS & 1.341 & n.d. & n.d. & 1 & 11 & 12 & 7 & 18.9 \\
\hline EET 96016 & NASA & 1.220 & 148 & 75 & n.d. & 36 & 259 & 170 & 89.4 \\
\hline EET 96029 & NASA & 1.000 & 23 & 14 & 9 & n.d. & 46 & 37 & 35.5 \\
\hline Erevan & RAS & n.m. & 12 & 1 & 4 & n.d. & 17 & n.m. & n.m. \\
\hline GRA 98074 & NASA & 0.203 & 49 & 16 & n.d. & 5 & 70 & 277 & 35.5 \\
\hline Kaidun & RAS & 3.611 & 8 & İ.Ó. & n.d. & 9 & 17 & 4 & 20.6 \\
\hline LEW 85311 & NASA & 1.483 & n.d. & 5 & n.d. & 9 & 14 & 8 & 29.8 \\
\hline MAC 88100 & NASA & 0.125 & 18 & 9 & 1 & 2 & 30 & 192 & 96.3 \\
\hline Mighei & RAS, NHM & 2.945 & 118 & 43 & 23 & 2 & 186 & 51 & 47.7 \\
\hline Murchison & RAS, NHM & 0.395 & 37 & 18 & n.d. & 7 & 62 & 126 & 27.1 \\
\hline Murray & NHM & 1.259 & 38 & 19 & 1 & 12 & 70 & 45 & 46.4 \\
\hline Nogoya & NHM & 0.681 & 58 & 16 & 17 & n.d. & 91 & 107 & 66.7 \\
\hline QUE 97077 & NASA & 0.865 & 36 & 24 & 2 & 6 & 68 & 63 & 63.1 \\
\hline Tagish Lake & NHM & 0.293 & 1 & 1 & 1 & n.d. & 3 & 8 & 17.6 \\
\hline Y-82042 & NHM & 1.056 & 47 & 11 & 1 & n.d. & 59 & 45 & 94.0 \\
\hline
\end{tabular}

Note: NHM, Naturhistorisches Museum, Wien, Austria; NASA, collection of iron meteorite of NASA, United States; AMNH, American Museum of Natural History, New York; and RAS, collection of meteorites of the Russian Academy of Sciences. n.d. denotes not detected; n.m., not measured; $P$, pentlandite; and Po, pyrrhotite.

results of our study and discussing their possible genetic consequences.

\section{SAMPLES AND METHODS}

Twenty four CM (or similar) chondrites were examined for the presence of P-bearing sulfides (Table 1). In addition, we searched for such sulfides in the Bali (CV3), Mokoia (CV3), Dhofar 015 (CK3), Krymka (LL3), and Manych (LL3) meteorites. Polished sections and thin sections of these meteorites were investigated using a JSM 6400 analytical scanning electron microscope at the Naturhistorisches Museum, Wien, in order to search for, identify, and analyze P-rich grains. All sulfide grains larger than $5 \mu \mathrm{m}$ were checked for the presence of $\mathrm{P}$ in most of the samples. The P-bearing sulfide grains were then subdivided into Cr-poor and Cr-rich ( $>1$ wt \%) suites. The number of such grains and their aggregates were counted in every section. In a similar manner, schreibersite, $\left((\mathrm{Fe}, \mathrm{Ni})_{3} \mathrm{P}\right)$, and barringerite, $\left((\mathrm{Fe}, \mathrm{Ni})_{2} \mathrm{P}\right)$, grains were counted. The latter minerals might be represented in part by allabogdanite or oxyphosphides (see below). In addition, the proportion of pyrrhotite and pentlandite grains was determined in every section (Table 1). The obtained data allowed us to estimate the absolute abundance of P-bearing opaque phases (Table 1), assuming that the mean size of their grains is $7 \mu \mathrm{m}$, the density is $4.5 \mathrm{~g} / \mathrm{cm}^{3}$, and the density of CM chondrites is $2.75 \mathrm{~g} / \mathrm{cm}^{3}$. The distribution of particles of these phases with respect to size was not investigated. Perhaps, particles of the assumed mean size dominate the number distribution but not the weight 
distribution. Therefore, the obtained absolute abundances are probably underestimated, and their accuracy is no better than one order of magnitude. Nonetheless, these data are relatively reliable for the determination of differences in the abundance of P-rich opaque phases between the CM chondrites studied.

Major elements were analyzed in P-bearing sulfides and coexisting phases with ARL (Naturhistorisches Museum, Wien) and Cameca SX-100 (Universität Wien) electron microprobes at an accelerating voltage of $15 \mathrm{kV}$, a beam current of $20 \mathrm{nA}$, a spot size of 1-2 $\mu \mathrm{m}$, and a counting time of $20 \mathrm{~s}$. The standards were mainly natural mineral phases. Trace elements were analyzed in some grains of P-bearing sulfides using a modified Cameca IMS-3f ion microprobe at the CRPG (Nancy, France) and Max-Planck-Institut für Chemie (Mainz, Germany). The analytical technique was described by Zinner and Crozaz (1986). The Raman spectra of several grains of P-bearing sulfides from the Cold Bokkeveld CM chondrite were recorded on a Dilor LABRAM confocal spectrometer with a frequency-doubled Nd-YAG laser (100 mW, $532.2 \mathrm{~nm})$, a diffraction grating (1800 grooves/mm), and a slow-scan CCD matrix detector.

\section{RESULTS}

\section{Abundance}

Phosphorus-bearing sulfides were not found in the LL, CV, and CK chondrites studied here. They were also absent in Acfer 094 and Dhofar 225, which are definitely anomalous carbonaceous chondrites. The former is a C2 or C3 chondrite (Bischoff and Geiger, 1994), and the latter is a thermally metamorphosed carbonaceous chondrite (Ivanova et al., 2002). Only a few grains of P-bearing sulfides were found in the Bells, Kaidun, Tagish Lake, and MAC 88100 chondrites (Table 1). Bells and MAC 88100 are CM chondrites, whereas Kaidun and Tagish Lake are anomalous $\mathrm{C}$ and C2 chondrites, respectively (Zolensky and Ivanov, 2003; Zolensky et al., 2002). All other CM chondrites usually contain accessory amounts of P-bearing sulfides, and these chondrites can be distinctly subdivided into two groups with respect to sulfide abundance. The first group includes the ALH 83100, ALH 84044, ALH 85013, Banten, Boriskino, Cold Bokkeveld, EET 96029, Mighei, Murray, Y-82042, and QUE 97077 chondrites containing about 20-70 ppm P-bearing sulfides (Table 1). The second group includes the Cochabamba, GRA 98074, MAC 88100, Murchison, and Nogoya chondrites containing more than $100 \mathrm{ppm}$ P-bearing sulfides. The highest content of P-bearing sulfides was observed in GRA 98074 (Table 1). Almost every fourth sulfide grain from this chondrite contains phosphorus. Banten, Dhofar 225, EET 96016, GRA 98074, Kaidun, LEW 85311, Murchison, and Murray contain schreibersite only, whereas the Cochabamba, EET 96029, Mighei, and Nogoya chondrites and CM clasts from the Erevan howardite contain barringerite only. Both phosphides, schreibersite and barringerite, were observed in other CM chondrites (Table 1). Phosphides were not found in the Bells and Y-82042 chondrites. The presence of P-bearing sulfides in the Murchison, Mighei, Cold Bokkeveld, and Boriskino chondrites was confirmed by Devouard and Buseck (1997) and Boctor et al. (2002). This phase was also reported from the clasts of CM chondrites from the Jodzie and Kapoeta howardites (Gounelle et al., 2003).

\section{Modes of Occurrence}

Phosphorus-bearing sulfides usually occur in CM chondrites in forsterite-pyroxene aggregates (Fig. 1a) surrounded by accretionary mantles. The pyroxene of these aggregates may be both enstatite and clinoenstatite. The latter is more common in CM chondrites (Brearley and Jones, 1999). Grains of P-bearing sulfides often decorate the surface of such aggregates (Fig. 1b). In those CM chondrites that are almost free of forsterite-pyroxene aggregates (for instance, ALH 83100), P-bearing sulfides are usually confined to phyllosilicate objects (Fig. 1c). In the matrix of CM chondrites, P-bearing sulfides occur as independent objects surrounded by accretionary mantles (Fig. 1d) or small fragments without such mantles.

With respect to mineral composition, objects containing P-bearing sulfides can be subdivided into monomineralic and complex. The former have irregular, angular, or rounded shapes and a more or less compact texture (Fig. 2). Such objects are usually no larger than $10 \mu \mathrm{m}$, although some of them may reach $50 \mu \mathrm{m}$ in size. The monomineralic aggregates consist mainly of P-bearing sulfide grains, a few micrometers in size. These grains are usually anhedral, but may occasionally have tabular shapes (Fig. 2b). Some of the objects contain barringerite or schreibersite inclusions morphologically similar to phases exsolved from a solid solution (Figs. 2e, 2f).

The complex aggregates are up to $100 \mu \mathrm{m}$ in size and irregular in shape. Barringerite and schreibersite are the most common phases associating with P-bearing sulfides in such objects. Barringerite forms lathlike crystals or rounded grains (Figs. 3a-3c). Schreibersite was observed as anhedral grains or acicular crystals intergrown with P-bearing sulfides (Fig. 3a). It should be noted that isolated grains (less than $10 \mu \mathrm{m}$ in size) of these phosphides occur also in the matrix of CM chondrites.

Eskolaite $\left(\mathrm{Cr}_{2} \mathrm{O}_{3}\right)$ was previously reported only from the unusual carbonaceous chondrite Belgica 79004 (Kimura and Ikeda, 1992) and the LEW 88774 ureilite (Prinz et al., 1994). It usually associates with Pbearing sulfides and phosphides. This phase was first discovered by us in CM clasts from the Erevan howardite (Nazarov et al., 1994) and has been subsequently identified in many $\mathrm{CM}$ chondrites. Eskolaite grains 

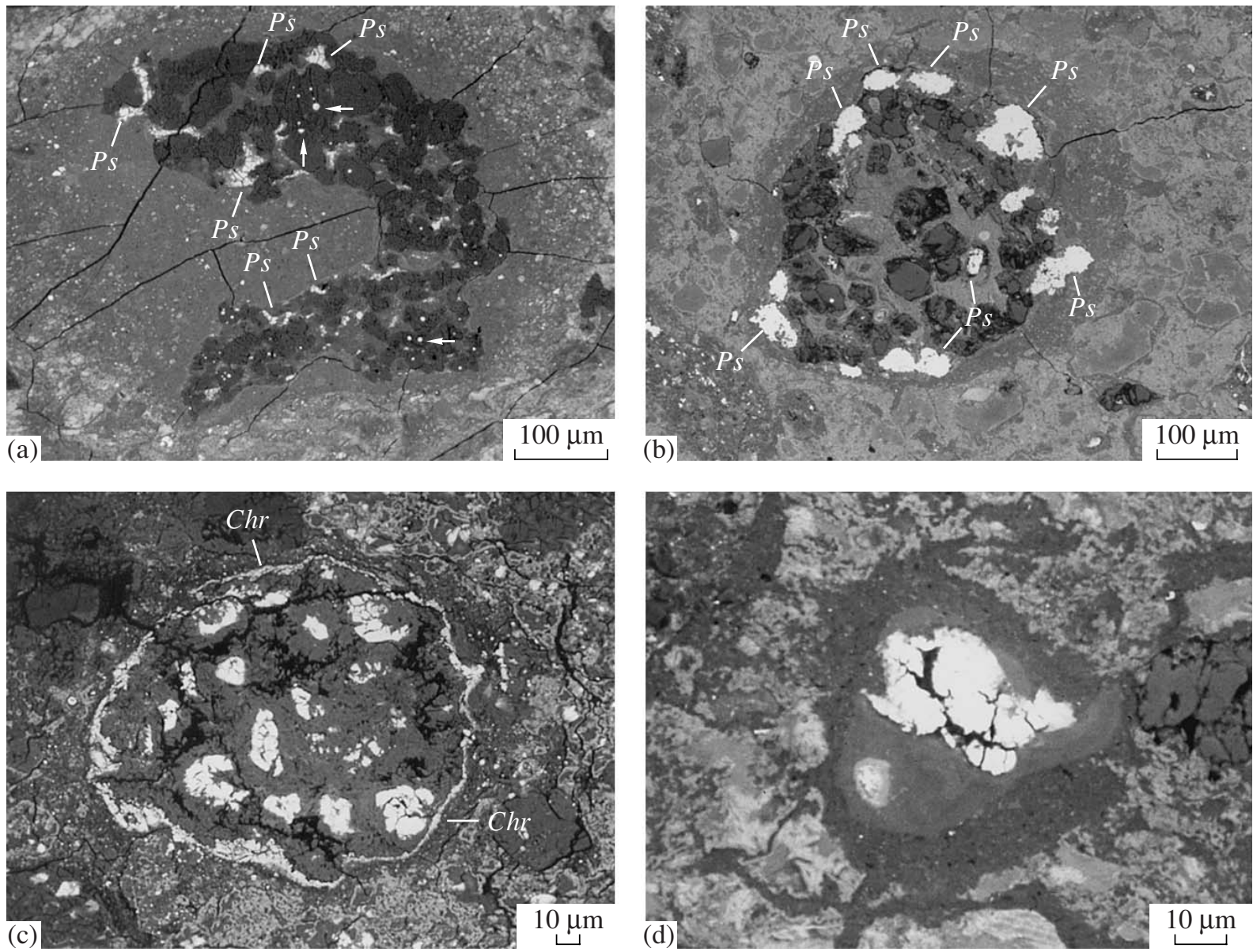

Fig. 1. Back-scattered electron images illustrating the occurrence of P-bearing sulfides in CM chondrites. (a) P-bearing sulfide (Ps) in a forsterite object surrounded by an accretionary mantle. Phyllosilicates occur in the interstices between the forsterite grains. The arrows indicate rounded inclusions of kamacite in forsterite. GRA 98074 meteorite. (b) P-bearing sulfide (Ps) decorating a forsterite aggregate, in which phyllosilicates fill the interstices of forsterite grains. Boriskino meteorite. (c) Grains of P-bearing sulfide (lightcolored) in an object consisting of phyllosilicates mantled by a thin layer of chromite (Chr) grains. ALH 83100 meteorite. (d) Object consisting of P-bearing sulfide grains (light-colored) surrounded by an accretionary mantle. Boriskino meteorite.

may be euhedral and are typically $1-5 \mu \mathrm{m}$ in size (Fig. 3c). They occur in intergrowths with P-bearing sulfides and phosphides, but are usually confined to the surface of complex aggregates. Eskolaite coexists sometimes with small crystals of Mg-rich chromite, but similar chromite occurs also in the aggregates of P-bearing sulfide without eskolaite. Small magnetite crystals were observed in rare cases in the aggregates of P-bearing sulfide. This assemblage was documented in the Banten, Nogoya, and Cochabamba chondrites. In Nogoya, magnetite crystals occur in direct contact with P-bearing sulfide (Fig. 3f). A very large rutile grain, about $100 \mu \mathrm{m}$ in size, was found in the Cold Bokkeveld chondrite. Such large rutile grains were previously never observed in chondrites. However, phosphide or P-bearing sulfide grains were not found near this rutile.

Despite the abundance of $\mathrm{Fe}-\mathrm{Ni}$ sulfides in $\mathrm{CM}$ chondrites, they never associate with P-bearing sulfides. Only in the Boriskino meteorite, corroded grains of P-bearing sulfide were found in intergrowths with pentlandite and $\mathrm{Fe}-\mathrm{Ni}$ sulfide at the margin of a forsterite aggregate (Fig. 3d). In contrast, daubreelite $\left(\mathrm{FeCr}_{2} \mathrm{~S}_{4}\right)$, which was found for the first time by us in CM chondrites (Nazarov et al., 1996), very often associates with P-bearing sulfides (Fig. 3a). This assemblage was documented in the Mighei, Banten, and Cochabamba chondrites. In Banten, daubreelite grains, up to $10 \mu \mathrm{m}$ in size, are intergrown with P-bearing sulfide. It is interesting that eskolaite coexists with daubreelite. Other sulfides that do not occur in contact with P-bearing sulfides but may be genetically related to them are brezinaite $\left(\mathrm{Cr}_{3} \mathrm{~S}_{4}\right)$ and a phase compositionally similar to djerfisherite $\left(\mathrm{K}_{6} \mathrm{Cu}_{2} \mathrm{Fe}_{24} \mathrm{~S}_{28} \mathrm{Cl}\right)$. These rare sulfides were identified for the first time in carbonaceous chondrites. Previously, brezinaite was reported only from the Tucson iron meteorite (Bunch and Fuchs, 1969), LEW 88774 ureilite (Prinz et al., 1994), and Mt. Egerton aubrite (Casanova et al., 1993). Djerfisherite is a common accessory phase in enstatite chondrites (Fuchs, 1966; El Goresy et al., 1988; Ikeda, 1989). Two 

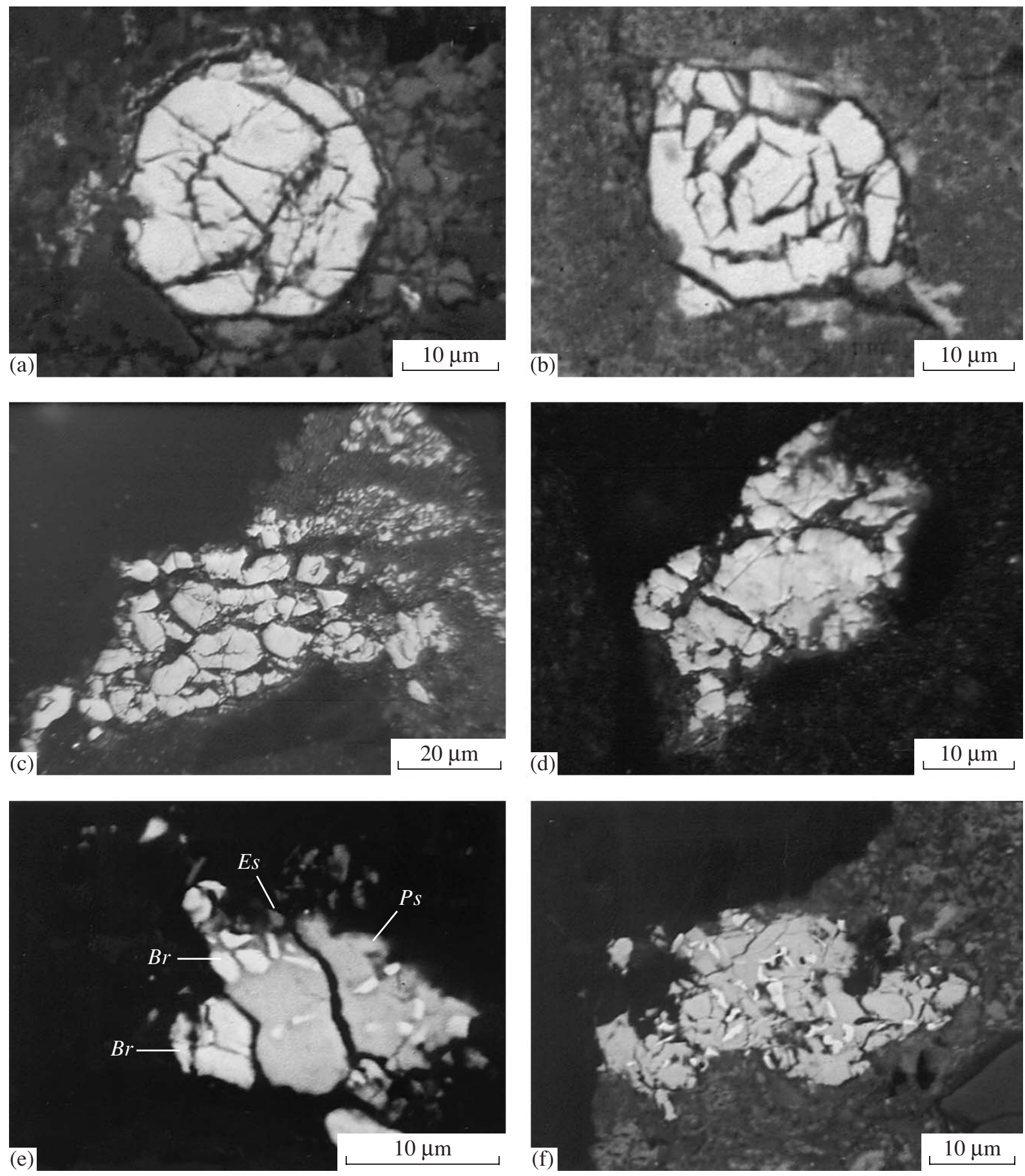

Fig. 2. Monomineralic inclusions of P-bearing sulfides in CM chondrites. (a) Rounded object composed of irregular grains of P-bearing sulfide in the Cold Bokkeveld meteorite. (b) Aggregate of tabular grains of P-bearing sulfide in the Banten meteorite. (c) Aggregate of anhedral grains of P-bearing sulfide in the Cold Bokkeveld meteorite. (d) Object of P-bearing sulfide oxidized along margins in the Boriskino meteorite. The central lighter part is weakly altered. (e) Object consisting of P-bearing sulfide (Ps) with inclusions (light) of barringerite $(\mathrm{Br})$ in the Boriskino meteorite. There are also small grains of eskolaite $(E s)$. (f) Fragment of P-bearing sulfide with schreibersite inclusions (light-colored) in the Murchison meteorite. Figures (a), (b), (e), and (f) are back-scattered electron images, and Figs. (c) and (d) are photomicrographs obtained on an optical microscope in reflected light with immersion oil. 

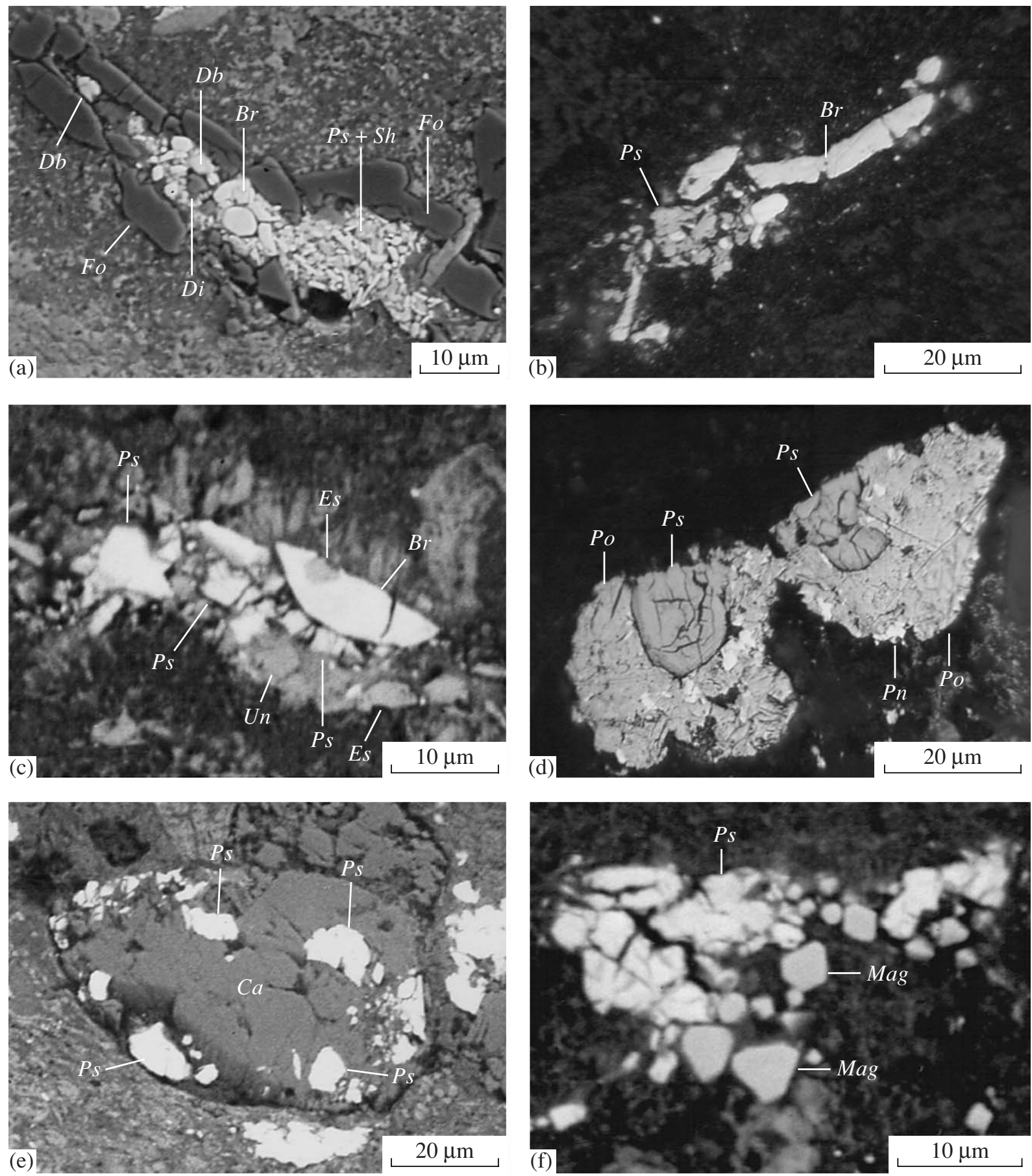

Fig. 3. Polymineralic aggregates and associations of grains with P-bearing sulfide $(P s)$ in $\mathrm{CM}$ chondrites. (a) Object with $\mathrm{P}$-bearing sulfide intergrown with acicular schreibersite crystals $(S h)$. Barringerite $(B r)$ occurs as rounded grains. There are also rare grains of daubreelite $(D b)$ and diopside $(D i)$. The whole object is surrounded by tabular forsterite grains (Fo). Mighei meteorite. (b) Lathlike barringerite crystals associate with irregular grains of P-bearing sulfide. Mighei meteorite. (c) Aggregate containing rounded barringerite grains and anhedral grains of P-bearing sulfide. Eskolaite $(E s)$ occurs as individual grains and small inclusions in barringerite. The object also contains an unknown phase (Un) consisting of $\mathrm{Ca}, \mathrm{Fe}, \mathrm{Si}$, and $\mathrm{S}$. Cochabamba meteorite. (d) Rounded grains of P-bearing sulfide intergrown with $\mathrm{Fe}-\mathrm{Ni}$ sulfide $(\mathrm{Po})$ and pentlandite $(\mathrm{Pn})$ at the margin of a forsterite aggregate. Boriskino meteorite. (e) Calcium carbonate grain with inclusions of P-bearing sulfide. Boriskino meteorite. (f) Association of P-bearing sulfide grains with magnetite (Mag) in the matrix of the Nogoya meteorite. Figures (a), (c), (e), and (f) are back-scattered electron images, and Figs. (b) and (d) are photomicrographs obtained on an optical microscope in reflected light with immersion oil. 


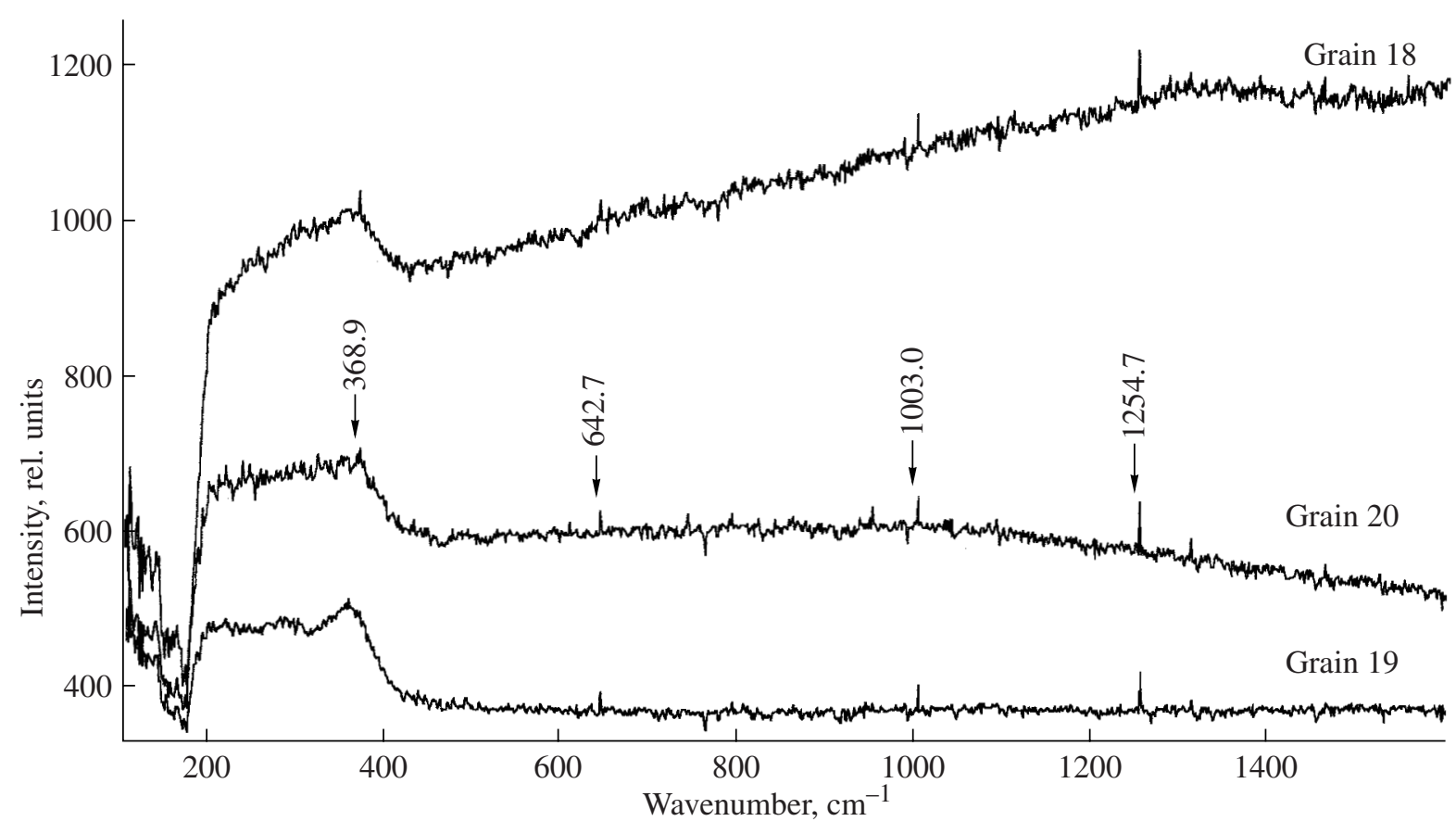

Fig. 4. Raman spectra of three P-bearing sulfide grains from the Cold Bokkeveld meteorite.

brezinaite grains, 3-7 $\mu \mathrm{m}$ in size, were found in Cochabamba. One of them is located in a forsterite object, which contains also P-bearing sulfide and barringerite grains, but these phases have no contacts with the brezinaite. Another brezinaite grain was found in the matrix and is surrounded by an Mg-rich chromite rim. A rounded grain $(10 \mu \mathrm{m}$ in diameter) compositionally similar to djerfisherite was found in the matrix of the Boriskino chondrite. This grain contains small inclusions of pentlandite along the margins.

Although it could have been expected that P-bearing sulfides would be replaced by phosphate and $\mathrm{Fe}-\mathrm{Ni}$ sulfide owing to oxidation, such an assemblage is rather uncommon and was observed only in Mighei and Cochabamba. In the Mighei chondrite, small Ca phosphate grains occur in contact with P-bearing sulfide, but there are no reaction relations in that case. On the other hand, a rim of Fe phosphate was observed on some grains of P-bearing sulfide from the same meteorite. The formation of this rim could be related to secondary alteration. The Cochabamba chondrite contains $\mathrm{Na}$ and Fe phosphate occurring in an aggregate of P-bearing sulfide grains. Carbonate also sometimes coexists with P-bearing sulfide. In Boriskino, $\mathrm{Ca}$ carbonate grains contain P-bearing sulfide inclusion (Fig. 3e). In the Cold Bokkeveld and ALH 83100 chondrites, dolomite associates with P-bearing sulfide. There are no reaction relations between the P-bearing sulfide and carbonates.

Among the silicates associating with P-bearing sulfides, forsterite, magnesian pyroxenes, diopside, and phyllosilicates were identified. The latter do not replace
P-bearing sulfides. However, it is replaced by tochilinite and Fe hydroxides. Metallic Fe was never found in association with P-bearing sulfides.

\section{Optical Properties and Raman Spectra}

With respect to reflectance, P-bearing sulfides are not very different from troilite and pyrrhotite. These phases can hardly be discriminated by routine optical microscopy. However, P-bearing sulfide is slightly darker (Fig. 3d) than pyrrhotite and troilite, because the presence of $\mathrm{P}$ probably reduces reflectance. In reflected light, the color of P-bearing sulfide depends on its composition. Sulfides with very high $\mathrm{P}$ contents are distinctly brownish, whereas low-P sulfides are yellow. The incorporation of $\mathrm{Cr}$ results in darker colors and development of grayish shades. No anisotropy effects were observed in reflected light.

Raman spectra were obtained for three grains of Pbearing sulfide from the Cold Bokkeveld chondrite (Fig. 4). They show some common features: (1) all the spectra are similar, which indicates that they are characteristic for this phase, and (2) all the spectra are rather flat, but exhibit four distinct (although weak) peaks at frequencies of $369,643,1003$, and $1255 \mathrm{~cm}^{-1}$. The obtained spectra are very different from the Raman spectra of pyrrhotite from the Zagami meteorite (Wang et al., 1998), which display a broad peak at $430 \mathrm{~cm}^{-1}$. 

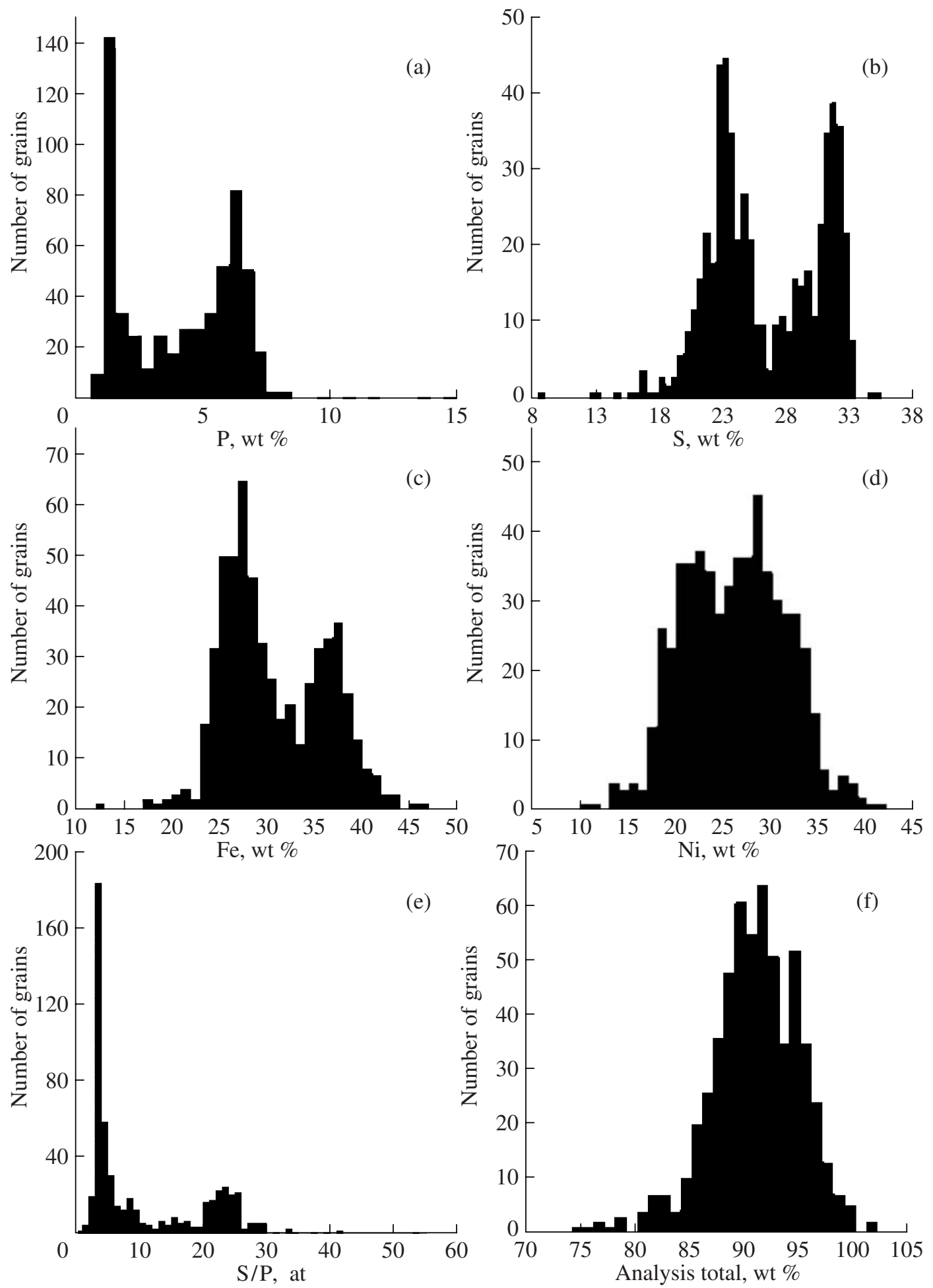

Fig. 5. Histograms of (a) P, (b) S, (c) Fe, and (d) Ni contents, (e) S/P ratio, and (f) analytical total for P-bearing sulfides. Only electron microprobe analyses were used. 


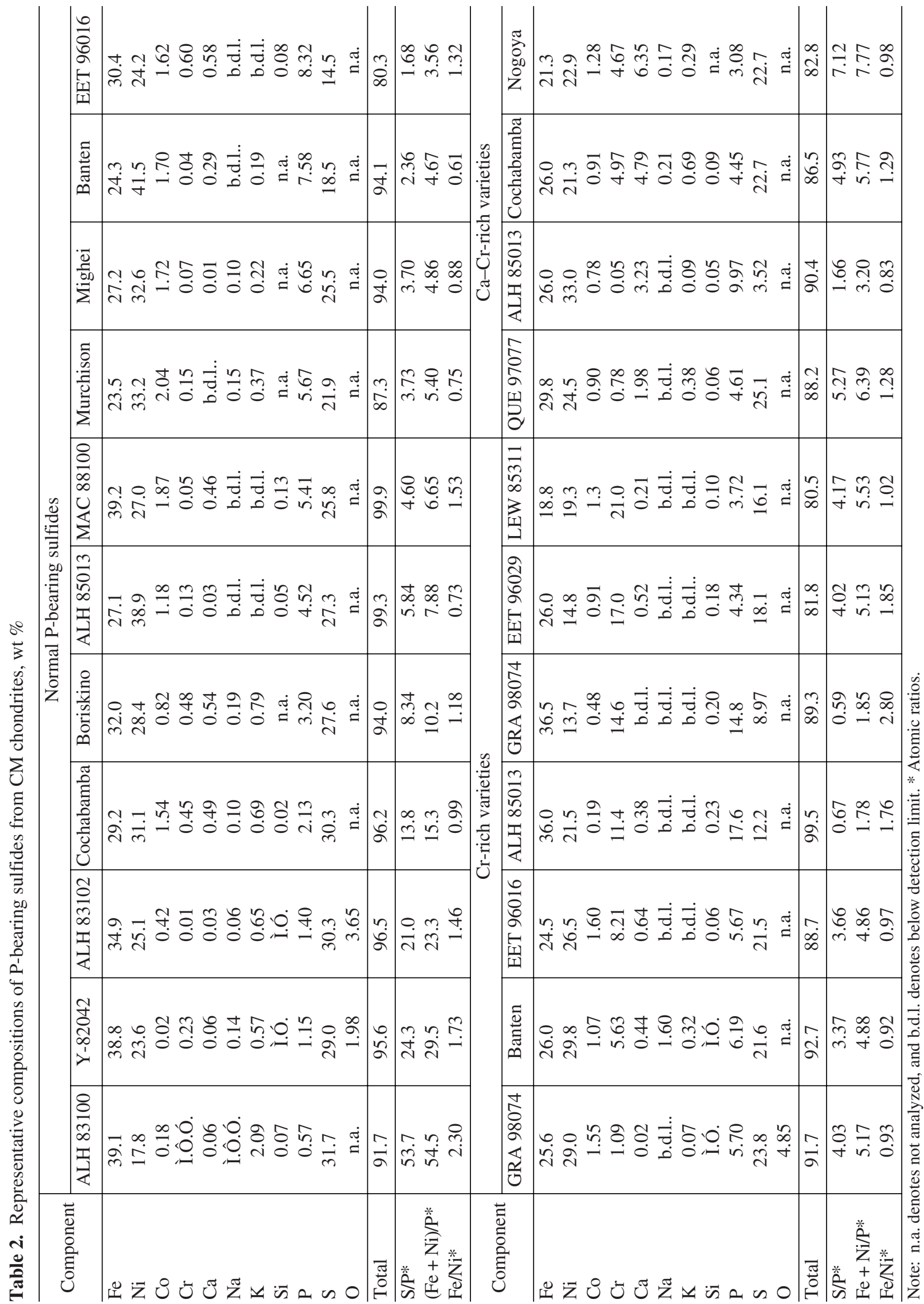

$\begin{array}{llll}\text { PETROLOGY Vol. } 17 & \text { No. } 2 & 2009\end{array}$ 

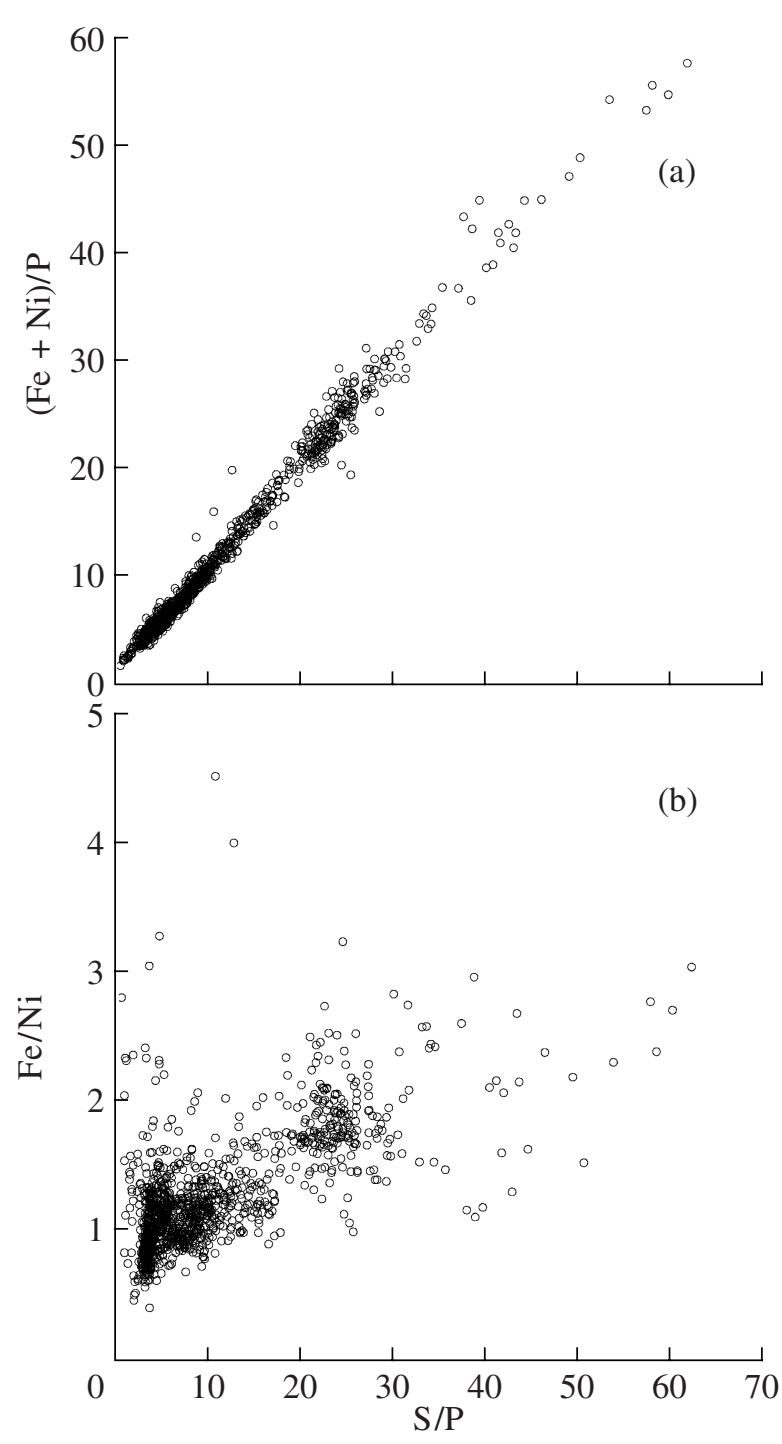

Fig. 6. Atomic ratios (a) $(\mathrm{Fe}+\mathrm{Ni}) / \mathrm{P}$ and (b) $\mathrm{Fe} / \mathrm{Ni}$ as functions of S/P in P-bearing sulfides according to the data of 1289 electron microprobe wavelength- and energy-dispersive analyses.

\section{Mineral Chemistry}

P-bearing sulfides. P-bearing sulfides contain (wt \%) 12-47 Fe, 10-42 Ni, 8-35 S, and 0.6-15 P (Table 2). The distribution of these elements (Fig. 5) indicates that there are two types of P-bearing sulfides, with low and high $\mathrm{S} / \mathrm{P}$ ratios, respectively. The mean composition of the first type shows an S/P atomic ratio of 4.8 and the following major element contents (wt \%): $5.5 \mathrm{P}, 23.8 \mathrm{~S}, 27.8 \mathrm{Fe}$, and $28.6 \mathrm{Ni}$; the second type has $\mathrm{S} / \mathrm{P}=24, \mathrm{P}=1.4, \mathrm{~S}=31.3, \mathrm{Fe}=36.3$, and $\mathrm{Ni}=$ 21.4. Despite these differences, all of the P-bearing sulfides fall on a common $\mathrm{S} / \mathrm{P}-(\mathrm{Fe}+\mathrm{Ni}) / \mathrm{P}$ trend (Fig. 6a). These atomic ratios show a very strong correlation (correlation coefficient of 0.995 for 1289 analyses), which can be described by the linear regression equation
$(\mathrm{Fe}+\mathrm{Ni}) / \mathrm{P}=0.965 \pm 0.003(1 \sigma) \cdot \mathrm{S} / \mathrm{P}+1.255 \pm 0.036(1 \sigma)$

The correlation between the $\mathrm{Fe} / \mathrm{Ni}$ and $\mathrm{S} / \mathrm{P}$ ratios is less pronounced (Fig. 6b), but high-S/P sulfides are systematically richer in $\mathrm{Fe}$ and poorer in $\mathrm{Ni}$ compared with low-S/P sulfides.

The characteristic minor elements of P-bearing sulfides are $\mathrm{Co}, \mathrm{Cr}, \mathrm{Ca}, \mathrm{K}$, and $\mathrm{Na}$ (Table 2). The content of Co reaches $3 \mathrm{wt} \%$ and correlates positively with $\mathrm{Ni}$, although the Ni/Co ratio is rather variable (Fig. 7a). The Ni-rich sulfides show low Ni/Co values compared with lower Ni sulfides. Many of the P-bearing sulfides contain more than $1 \mathrm{wt} \% \mathrm{Cr}$. The highest $\mathrm{Cr}$ content is 22 wt \%. Chromium does not correlate with other elements. Nonetheless, Cr- and P-bearing sulfides usually show low S/P ratios (Fig. 7b) and low contents of Fe, $\mathrm{Ni}, \mathrm{S}$, and $\mathrm{P}$ compared with ordinary P-bearing sulfides. Some of the P-bearing sulfides contain Ca (up to $12 \mathrm{wt}$ $\%)$. The enrichment of $\mathrm{Ca}$ is especially common in $\mathrm{Cr}-$ bearing sulfides from the Cochabamba chondrite but was also noted in ordinary P-bearing sulfides. The incorporation of $\mathrm{Cr}$ and $\mathrm{Ca}$ does not affect the aforementioned $(\mathrm{Fe}+\mathrm{Ni}) / \mathrm{P}-\mathrm{S} / \mathrm{P}$ relationship; i.e., the compositions of P-bearing sulfides enriched in $\mathrm{Ca}$ and $\mathrm{Cr}$ plot along the same regression line (Fig. 6a). The contents of alkali elements ( $\mathrm{K}$ and $\mathrm{Na}$ ) are up to $2 \mathrm{wt} \%$. Potassium is more common and weakly correlates with Fe. Sodium is characteristic mainly of P-bearing sulfides from the Banten chondrite. The contents of other elements ( $\mathrm{Si}, \mathrm{Ti}, \mathrm{Al}, \mathrm{Mn}, \mathrm{Mg}$, and $\mathrm{Cl}$ ) are usually below the detection limits.

The P-bearing sulfides have usually low analytical totals (Fig. 5f), although there are analyses with totals approaching $100 \%$. The deficit in analytical totals is higher than the accuracy of electron microprobe analysis and does not correlate with the compositional parameters of P-bearing sulfides. Only $\mathrm{Cr}$ - and Ca-rich sulfides show a negative correlation between the contents of these elements and the analytical total (Figs. 7c, $7 d)$.

There is no zoning within P-bearing sulfide grains and systematic variations in chemical composition within the aggregates of P-bearing sulfides. Only sulfide grains from the Cochabamba chondrite show a core to rim increase in $\mathrm{Ca}$ content. No systematic differences were also detected between the chemical compositions of P-bearing sulfides depending on their textural position in $\mathrm{CM}$ chondrites. However, P-bearing sulfides from different $\mathrm{CM}$ chondrites are chemically distinctly different (Fig. 8, Table 3). For instances, Murchison, Murray, EET 96016, GRA 98074, Banten, LEW 85311, EET 96029, QUE 97077, and MAC 88100 contain sulfides with low S/P ratios and very minor compositional variations. All of these sulfides belong to the first cluster with low S/P ratios (Fig. 5b). Other CM chondrites contain $\mathrm{P}$-bearing sulfides with high $\mathrm{S} / \mathrm{P}$ and $\mathrm{Fe} / \mathrm{Ni}$ values and strongly variable chemical compositions. These sulfides fall within cluster 2 and dominate in ALH 83100, ALH 83102, ALH 84029, and Y-82042. 

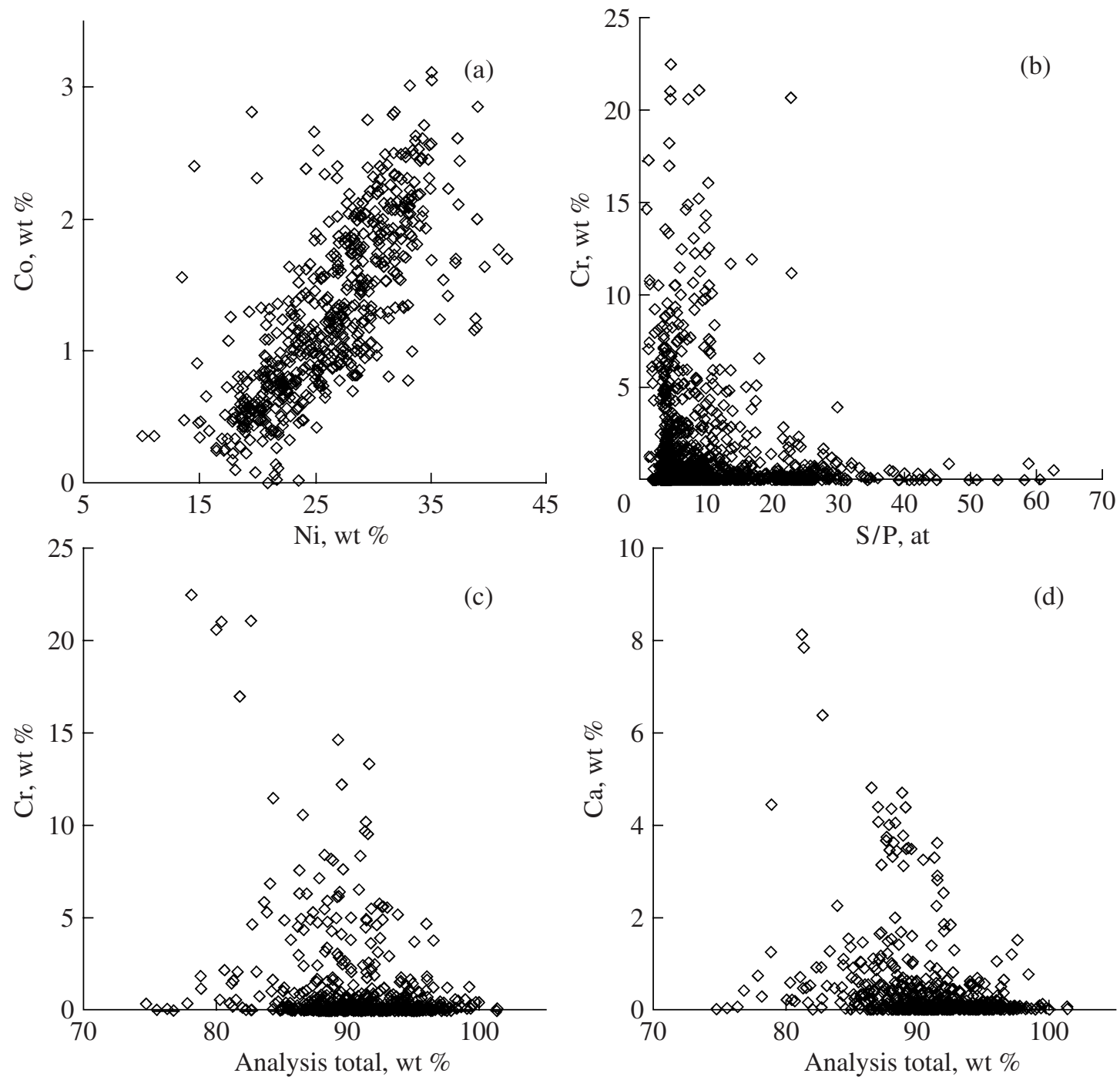

Fig. 7. Contents of minor elements in P-bearing sulfides. (a) Direct correlation of Co and Ni. (b) High contents of Cr are observed in sulfides with low $\mathrm{S} / \mathrm{P}$ ratios. (c) Some $\mathrm{Cr}$-rich sulfides show a negative correlation between $\mathrm{Cr}$ content and analytical total. (d) The same tendency is characteristic of sulfides with elevated Ca contents.

The Cold Bokkeveld, Mighei, and Cochabamba chondrites and CM clasts from the Erevan howardite contain P-bearing sulfides of transitional compositions, whereas the ALH 84044, Nogoya, ALH 85013, and Boriskino chondrites contain P-bearing sulfides of all types.

Phosphides and oxyphosphides. Barringerite and oxyphosphides from CM chondrites show considerable variations in $\mathrm{Fe} / \mathrm{Ni}$ (Fig. 9a, Table 4) compared with barringerite from iron meteorites (Brandstätter et al., $2003)$. The mean $(\mathrm{Fe}+\mathrm{Ni}) / \mathrm{P}$ atomic ratio calculated from 184 barringerite analyses is $1.83 \pm 0.19(1 \sigma)$. A typical admixture element is Co (Figs. 9a, 9b). In some cases, S (up to 4 wt \%), $\mathrm{Cr}$ (up to 5 wt \%), and Ca were reported (Fig. 9c). Cobalt shows no correlation with Ni. Nonetheless, barringerites with $\mathrm{Fe} / \mathrm{Ni}>1$ or $\mathrm{Ni}<40 \mathrm{wt} \%$ are significantly depleted in Co (Figs. 9a, 9b). In con- trast, Ni-rich barringerite $(\mathrm{Fe} / \mathrm{Ni}<1)$ may be rich in $\mathrm{Co}$ (up to $3.5 \mathrm{wt} \%$ ) and is probably allabogdanite, a recently discovered (Britvin et al., 2002) modification of $(\mathrm{Fe}, \mathrm{Ni})_{2} \mathrm{P}$ with the $\mathrm{Co}_{2} \mathrm{P}$ structure. The possible occurrence of this modification was previously predicted by Nazarov et al. (1998). High-Cr barringerite was found in Dhofar 225 (Table 4). High Ca contents are most common in barringerite from the Cochabamba chondrite (Nazarov et al., 2000) but were also indicated in this mineral from other CM chondrites. There is a significant negative correlation between the Ca content and analytical totals of Ca-rich barringerite (Fig. 9c), although there are also Ca-poor varieties with low analytical totals. This correlation suggests that $\mathrm{Ca}$ is incorporated in such phosphides together with a light element, most likely, oxygen. The amount of oxygen estimated from the deficit of total is sufficient to oxidize all of the $\mathrm{Ca}$, but not other elements, which must remain in 


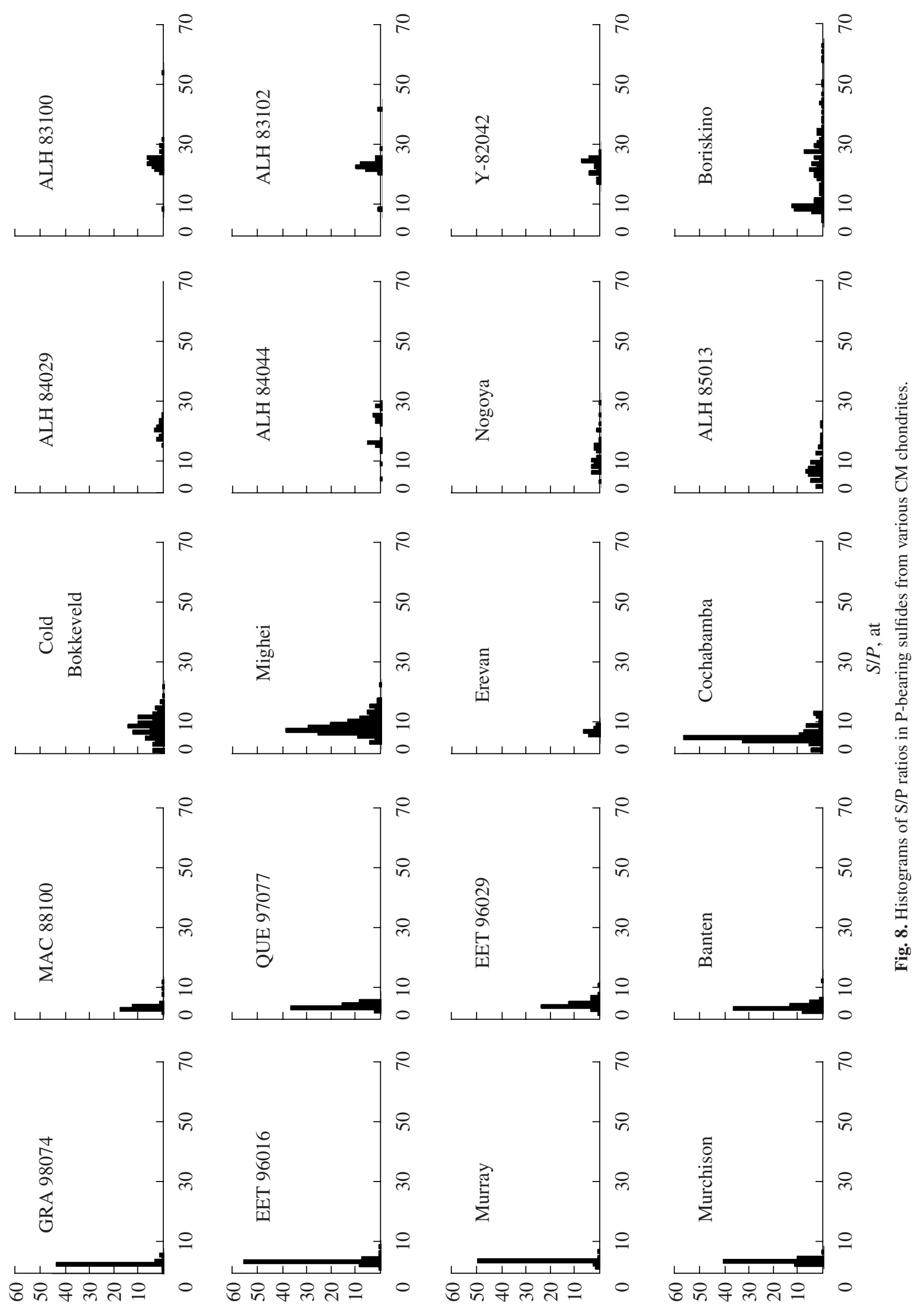


Table 3. Average chemical characteristics of P-bearing sulfides from CM chondrites (atomic ratios)

\begin{tabular}{l|c|c|c|c}
\hline \multicolumn{1}{c|}{ Meteorite } & $\mathrm{S} / \mathrm{P}$ & $(\mathrm{Fe}+\mathrm{Ni}) / \mathrm{P}$ & $\mathrm{Fe} / \mathrm{Ni}$ & Number of analyses \\
\hline Murchison & $3.36(0.84)$ & $4.54(0.80)$ & $0.93(0.22)$ & 68 \\
Murray & $3.40(0.52)$ & $4.55(0.59)$ & $0.85(0.11)$ & 54 \\
EET 96016 & $3.54(0.84)$ & $4.90(0.73)$ & $1.02(0.18)$ & 77 \\
GRA 98074 & $3.58(0.87)$ & $5.02(0.90)$ & $0.92(0.36)$ & 50 \\
Banten & $3.78(1.28)$ & $5.22(1.22)$ & $0.99(0.25)$ & 70 \\
LEW 85311 & $3.82(0.80)$ & $5.10(0.68)$ & $1.07(0.08)$ & 4 \\
EET 96029 & $4.14(1.57)$ & $5.62(1.58)$ & $1.44(0.81)$ & 52 \\
QUE 97077 & $4.17(1.24)$ & $5.47(1.64)$ & $1.20(0.55)$ & 66 \\
MAC 88100 & $4.61(1.98)$ & $6.67(3.15)$ & $1.33(0.87)$ & 37 \\
Cochabamba & $5.92(2.43)$ & $6.58(2.48)$ & $1.12(0.19)$ & 139 \\
Erevan (CM clasts) & $6.67(0.90)$ & $8.15(0.96)$ & $1.27(0.19)$ & 17 \\
Mighei & $8.75(3.00)$ & $9.37(2.92)$ & $1.10(0.20)$ & 182 \\
Cold Bokkeveld & $9.10(4.14)$ & $9.94(4.06)$ & $1.20(0.26)$ & 108 \\
ALH 85013 & $9.20(6.76)$ & $10.1(6.65)$ & $1.14(0.30)$ & 50 \\
Nogoya & $12.4(6.14)$ & $13.2(6.01)$ & $1.21(0.27)$ & 26 \\
ALH 84044 & $20.47(6.21)$ & $21.12(5.78)$ & $1.49(0.36)$ & 30 \\
ALH 84029 & $20.8(2.66)$ & $21.5(2.67)$ & $1.93(0.24)$ & 20 \\
Boriskino & $22.0(13.1)$ & $22.1(12.3)$ & $1.61(0.51)$ & 120 \\
Y-82042 & $22.8(2.55)$ & $25.1(3.00)$ & $2.07(0.38)$ & 30 \\
ALH 83102 & $23.35(5.51)$ & $23.05(5.17)$ & $1.86(0.23)$ & 39 \\
ALH 83100 & $24.83(5.88)$ & $25.17(5.83)$ & $1.81(0.32)$ & 40 \\
\hline No Stan) & & & \\
\hline
\end{tabular}

Note: Standard deviation is given in parentheses.

the reduced state. Therefore, such compounds should be considered as oxyphosphides. Oxyphosphide grains are usually zoned and their Ca content increases from core to rim. It is interesting that some oxyphosphide fragments have no continuous Ca-rich zone at the contact with the chondrite matrix. The maximum $\mathrm{Ca}$ content $(10.9 \mathrm{wt} \%)$ was detected in an oxyphosphide grain from the Mighei chondrite (Table 4). The composition of this phase can be expressed by formulas with different $\mathrm{H}$ and $\mathrm{O}$ contents, for instance, $\mathrm{Ca}(\mathrm{Fe}, \mathrm{Ni})_{3}\left[\mathrm{PO}_{2}\right]_{2}$, $\mathrm{Ca}(\mathrm{Fe}, \mathrm{Ni})_{3} \mathrm{P}_{2} \cdot 4 \mathrm{H}_{2} \mathrm{O}$, or $\mathrm{Ca}(\mathrm{Fe}, \mathrm{Ni})_{3} \mathrm{P}_{2}[\mathrm{OH}]_{4}$. The barringerite and oxyphosphides coexist with $\mathrm{P}$-bearing sulfides having Fe/Ni $>1$ (Fig. 9d). The Fe/Ni ratios of coexisting sulfides and phosphides are negatively correlated; i.e., Ni-rich sulfides tend to associate with $\mathrm{Fe}$ rich barringerites and oxyphosphides.

The schreibersite shows a mean $(\mathrm{Fe}+\mathrm{Ni}) / \mathrm{P}$ atomic ratio of $2.85 \pm 0.11(1 \sigma)$ (97 analyses). The $\mathrm{Fe} / \mathrm{Ni}$ and $\mathrm{Ni} / \mathrm{Co}$ values of this mineral (Figs. 9a, 9b) are strongly variable, which is similar to barringerite and oxyphosphides. However, the Fe/Ni ratio of schreibersite is usually higher than that of associated P-bearing sulfides and barringerite (Fig. 9d). Schreibersite is usually not observed in association with P-bearing sulfides showing $\mathrm{Fe} / \mathrm{Ni}>1.2$. The $\mathrm{Cr}$ content of schreibersite is within $0.1-0.5 \mathrm{wt} \%$, and $\mathrm{Ca}$ is below the detection limit.

Other mineral phases. As was noted above, pentlandite and $\mathrm{Fe}-\mathrm{Ni}$ sulfide were found in association with P-bearing sulfide only in one case, in the Boriskino meteorite (Fig. 3d). These minerals contain 29.2 and $6.8 \mathrm{wt} \% \mathrm{Ni}$, respectively, and their atomic ratios are $(\mathrm{Fe}+\mathrm{Ni}) / \mathrm{S}=1.11$ and 1.01 and $\mathrm{Fe} / \mathrm{Ni}=1.29$ and 8.55, respectively. The Fe-Ni sulfide could be identified as mackinawite on the basis of relatively high $(\mathrm{Fe}+\mathrm{Ni}) / \mathrm{S}$ value, but this suggestion is inconsistent with its optical isotropy. The P-bearing sulfide coexisting with these sulfides is $\mathrm{Cr}$-poor and shows $\mathrm{S} / \mathrm{P}=28.4$ and $\mathrm{Fe} / \mathrm{Ni}=$ 1.88 .

The $\mathrm{Cr}$ sulfides daubreelite $\left(\mathrm{FeCr}_{2} \mathrm{~S}_{4}\right)$ and brezinaite $\left(\mathrm{Cr}_{3} \mathrm{~S}_{4}\right)$ incorporate a few admixture elements (Table 4). In particular, daubreelite contains $1.0-1.5 \mathrm{wt} \% \mathrm{Ni}$, and brezinaite contains about 3 wt $\% \mathrm{Fe}$ and $1 \mathrm{wt} \% \mathrm{Ni}$.

Djerfisherite from Boriskino (Table 4) has the formula $\left(\mathrm{K}_{5.2} \mathrm{Fe}_{18.2} \mathrm{Ni}_{8.4}\right)_{31.8} \mathrm{~S}_{28} \mathrm{Cl}$. As compared to djerfisherite $\left(\mathrm{K}_{6} \mathrm{Cu}_{2} \mathrm{Fe}_{24} \mathrm{~S}_{28} \mathrm{Cl}\right)$ from enstatite chondrites, aubrites, and ureilites (Fuchs, 1966; El Goresy et al., 1988; Ikeda, 1989), this phase is poorer in K, richer in $\mathrm{Fe}$ and $\mathrm{Ni}$, has very high $\mathrm{Ni} / \mathrm{Fe}$ ratio, and is almost free of $\mathrm{Cu}$. 

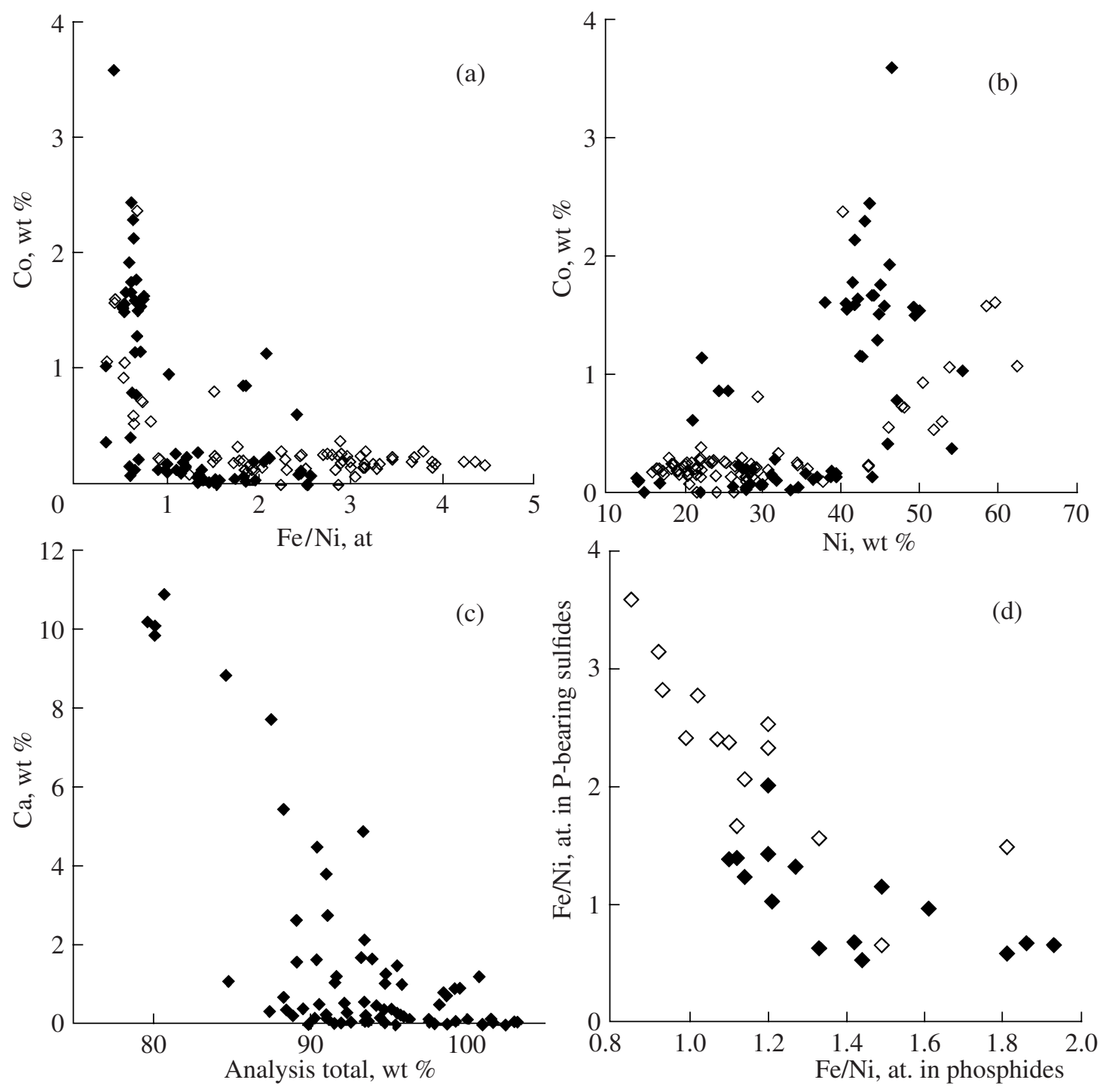

Fig. 9. Chemical compositions of phosphides and oxyphosphides. Filled diamonds are barringerite and oxyphosphides, and unfilled diamonds are schreibersite. (a) High Co contents were detected in phosphides and oxyphosphides with low Fe/Ni ratios. (b) Enrichment in Co is typical of phosphides and oxyphosphides with high Ni contents. (c) Some barringerite and oxyphosphide grains are enriched in $\mathrm{Ca}$, whose content increases with decreasing analytical total. (d) Mean Fe/Ni ratios in P-bearing sulfides and phosphides from various $\mathrm{CM}$ chondrites.

The eskolaite is almost pure $\mathrm{Cr}_{2} \mathrm{O}_{3}$ (Table 4) and contains only minor amounts of $\mathrm{Fe}$, $\mathrm{V}$, and $\mathrm{Mn}$. The rutile grain from the Cold Bokkeveld chondrite contains small amounts of $\mathrm{Fe}$ and $\mathrm{Mn}$ (Table 4).

The $\mathrm{Na}-\mathrm{Fe}$ phosphate associating with P-bearing sulfide and barringerite in the Cochabamba chondrite was difficult to analyze because of the high volatility of $\mathrm{Na}$ and $\mathrm{Cl}$ under the electron beam and the small grain size. The contents of $\mathrm{Na}$ and $\mathrm{Cl}$ (Table 4) were calculated from the $\mathrm{Na} / \mathrm{Fe}$ and $\mathrm{Cl} / \mathrm{Fe}$ ratios measured on a scanning electron microscope and the electron microprobe analysis of $\mathrm{Fe}$. Both methods yielded identical $\mathrm{Fe} / \mathrm{P}$ ratios. According to these data, the approximate formula of this phase is $\mathrm{Na}_{7} \mathrm{Fe}_{5}\left[\mathrm{P}_{3} \mathrm{O}_{10}\right]_{3} \mathrm{Cl}_{2}$, which suggests that it may be a polyphosphate. In contrast to orthophosphates, polyphosphates were previously unknown in nature and are poorer in oxygen and have a low cation to phosphorus ratio.

The compositions of olivine and pyroxenes associating with P-bearing sulfides are typical of CM chondrites (e.g., Brearley and Jones, 1999). Diopside (Fig. 3a) is poor in Fe and rich in $\mathrm{Al}_{2} \mathrm{O}_{3}(3$ wt \%) and $\mathrm{TiO}_{2}$ (1.3 wt \%). Tochilinite replacing P-bearing sulfides is usually richer in $\mathrm{Na}, \mathrm{Cr}, \mathrm{Ni}, \mathrm{P}$, and Co compared with ordinary tochilinites from $\mathrm{CM}$ chondrites.

\section{Trace Elements and Sulfur Isotopes}

Trace elements were analyzed in several grains of P-bearing sulfide from the Cold Bokkeveld and Nogoya 


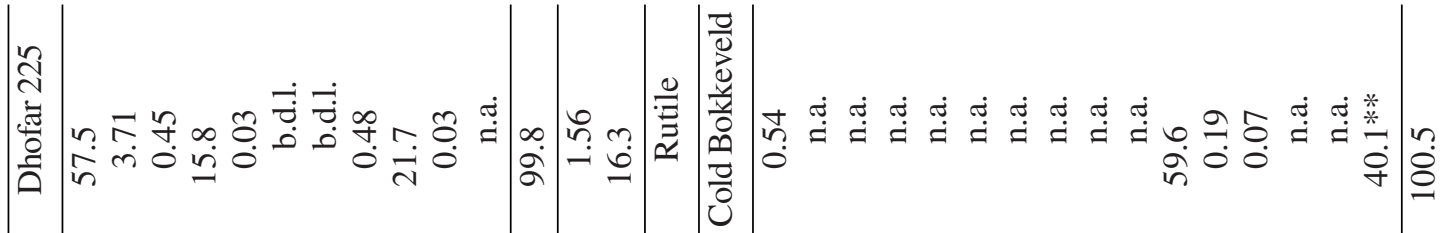

令

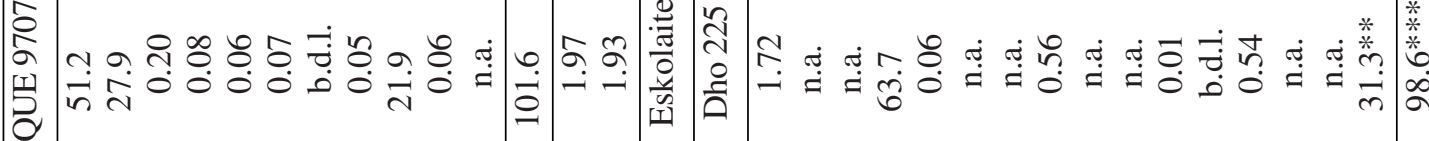

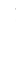

章

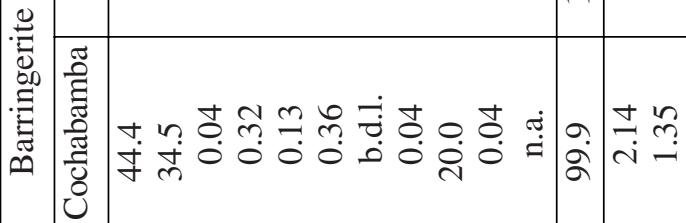

m

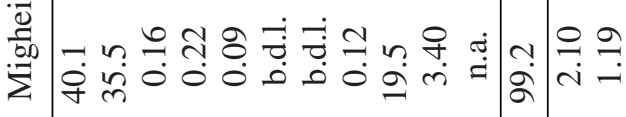

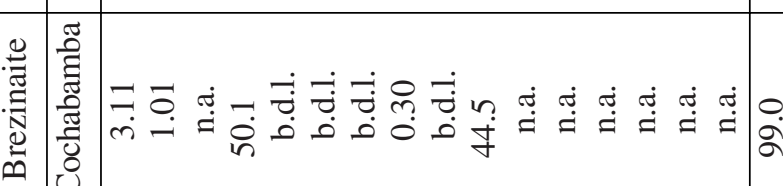

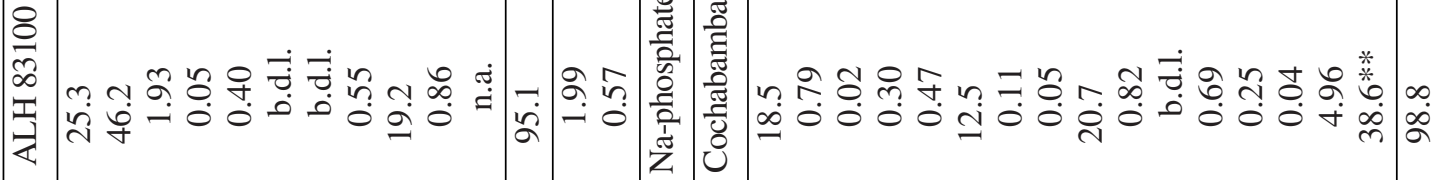

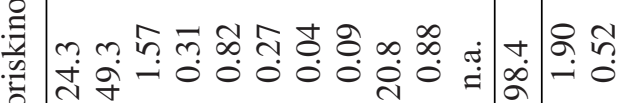

.

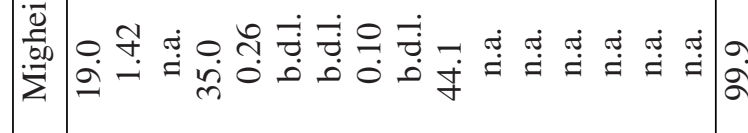
(n)

$\frac{6}{0}$

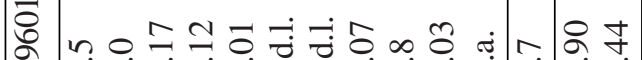
至

ต $ๆ$ กิ

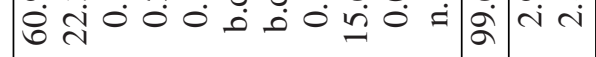

可 仿

m

ஜ 岁

要

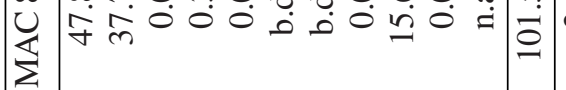

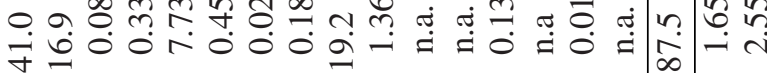

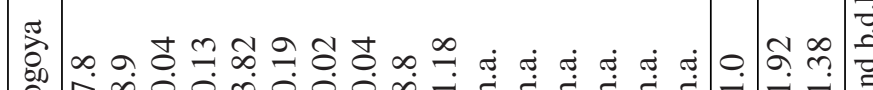

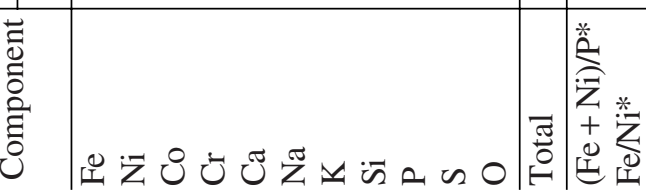
z m ल U

PETROLOGY Vol. $17 \quad$ No. $2 \quad 2009$ 

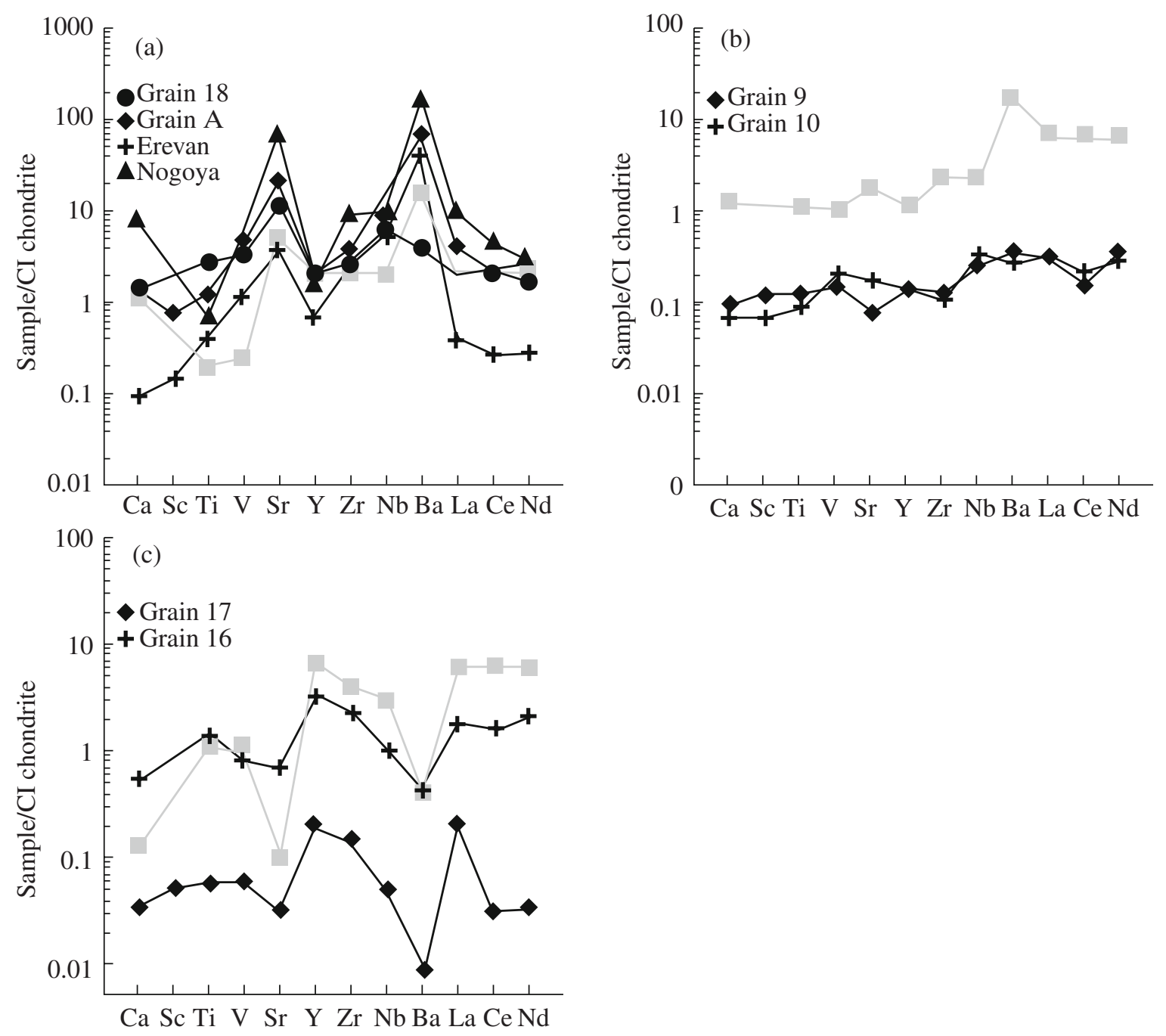

Fig. 10. Trace element patterns normalized to the CI chondrite composition (Anders and Grevesse, 1989) for P-bearing sulfides from the Cold Bokkeveld (grains A, 9, 10, 16, 17, and 18), Nogoya, and Erevan meteorites. For the sake of comparison, also shown are the model distribution of element contents in the SiC grains of extrasolar origin (Lodders and Fegley, 1995) normalized to CI chondrite and $\mathrm{Si}$ content in these chondrites and $\mathrm{SiC}$ (Amari et al., 1995). (a) SiC grains condensed at $1250 \mathrm{~K}$. The abundances of $s$ process elements in the initial gas are ten times the solar abundances; and $90 \%$ of $\mathrm{Ti}, \mathrm{V}, \mathrm{Zr}, \mathrm{Nb}, \mathrm{Y}$, and REEs were eliminated with earlier condensates. (b) Compositions of SiC grains at $1250 \mathrm{~K}$. The contents of s-process elements are higher than the solar values by a factor of 3 ; Y, by a factor of $1.5 ; \mathrm{Ba}$, by a factor of 10 ; and REEs, by a factor of 8 . Sixty five percent $\%$ of Ti, V, Zr, Nb, Y, and REEs were removed with earlier condensates. (c) Compositions of SiC grains at $1300 \mathrm{~K}$. The enrichment in $s$-process elements by a factor of 3 was accompanied by the elimination of $46 \%$ of $\mathrm{Ti}, \mathrm{V}, \mathrm{Zr}$, and $\mathrm{Nb}$ with earlier condensates.

meteorites and a CM clast in the Erevan howardite (Table 5). In Cold Bokkeveld, grains from forsteritepyroxene aggregates were analyzed. Grains 9 and 10 are from a single aggregate, grains 16 and 17 are from a different aggregate, and grains 18 and A occur in different objects. The grains from Erevan and Nogoya are individual fragments of P-bearing sulfide from the matrix. The analyzed grains (Table 5) represent all of the chemical types of P-bearing sulfides described above. All of them contain lithophile trace elements, whose contents directly correlate with $\mathrm{Ca}$. The $\mathrm{Sc} / \mathrm{Ca}$, $\mathrm{Ti} / \mathrm{Ca}$, and $\mathrm{V} / \mathrm{Ca}$ ratios approach the chondritic values, whereas the $\mathrm{Nb} / \mathrm{Ca}, \mathrm{Y} / \mathrm{Ca}, \mathrm{Zr} / \mathrm{Ca}, \mathrm{Sr} / \mathrm{Ca}, \mathrm{Ba} / \mathrm{Ca}$, and $\mathrm{La} / \mathrm{Ca}$ values are nonchondritic. The contents of litho- phile elements are not high, and the P-bearing sulfides can be subdivided into three types on the basis of their proportions (Fig. 10).

(1) Grain A from Cold Bokkeveld and grains from Nogoya and Erevan are strongly enriched in $\mathrm{Sr}$ and $\mathrm{Ba}$ relative to other elements and $\mathrm{Sr}$ and $\mathrm{Ba}$ abundances in CI chondrites (Fig. 10a). The contents of lithophile elements in these grains increase with increasing atomic number. The elements lighter than $\mathrm{V}$ show chondritic or almost chondritic abundances, whereas the heavier elements are enriched relative to CI chondrites. The lithophile element contents in a grain from Erevan show some specific features. They are generally lower than in other grains and increase in the sequence $\mathrm{Ca}, \mathrm{Sc}, \mathrm{Ti}, \mathrm{V}$, 


\begin{tabular}{|c|c|c|c|c|}
\hline & \multirow{2}{*}{ 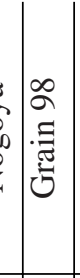 } & \multirow{2}{*}{ 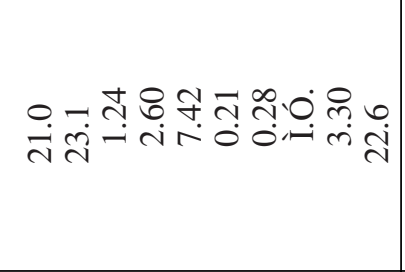 } & \multirow{2}{*}{$\frac{r}{\infty}$} & 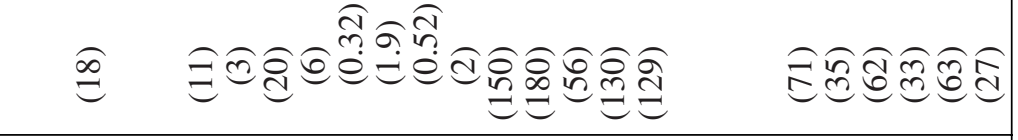 \\
\hline 咅 & & & & 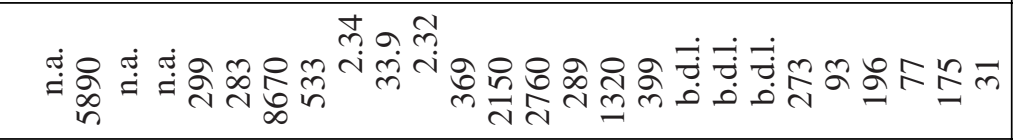 \\
\hline & \multirow{2}{*}{ 『 } & \multirow{2}{*}{ 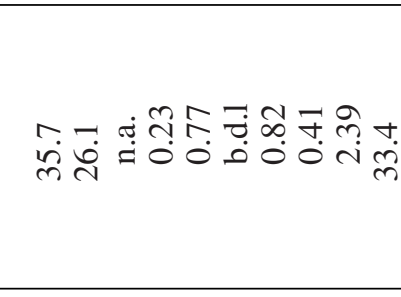 } & \multirow{2}{*}{$\infty$} & 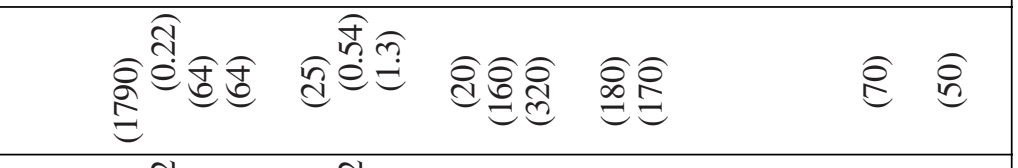 \\
\hline & & & & 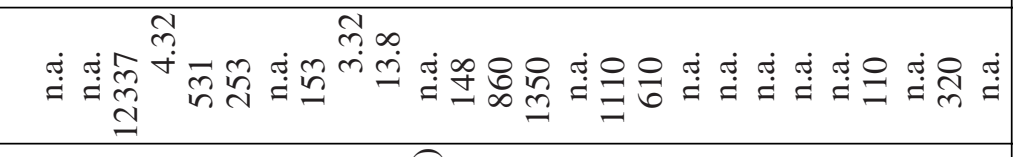 \\
\hline & \multirow{2}{*}{$\underset{\Xi}{\Xi}$} & \multirow{2}{*}{ 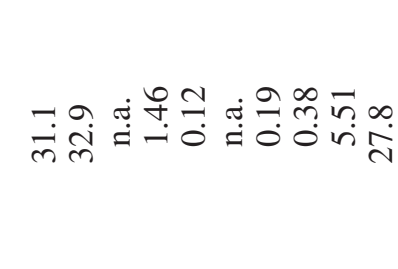 } & \multirow{2}{*}{ å } & 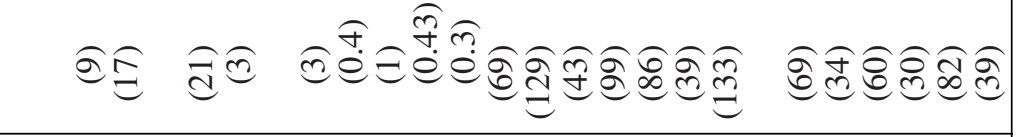 \\
\hline & & & & 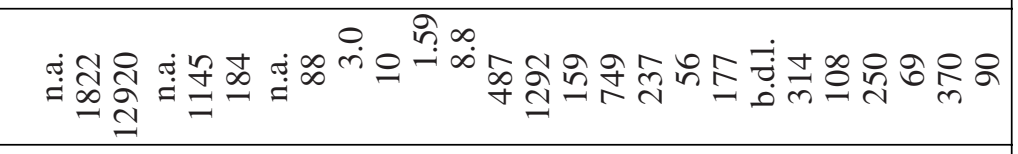 \\
\hline \multirow{4}{*}{\multicolumn{2}{|c|}{ 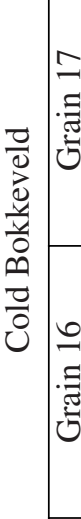 }} & \multirow{2}{*}{ 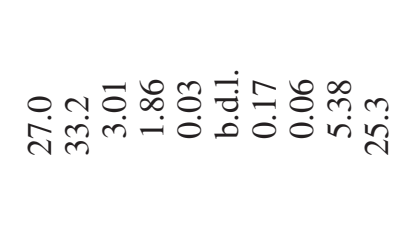 } & \multirow{2}{*}{ : } & 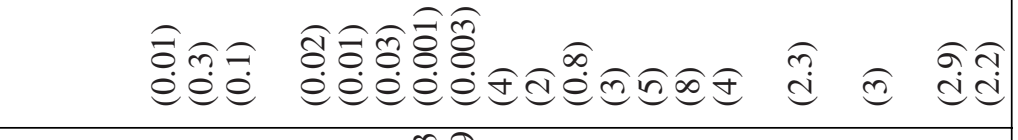 \\
\hline & & & & 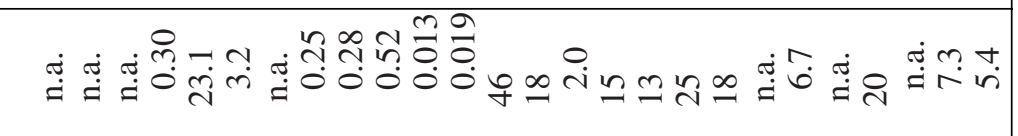 \\
\hline & & \multirow{2}{*}{ 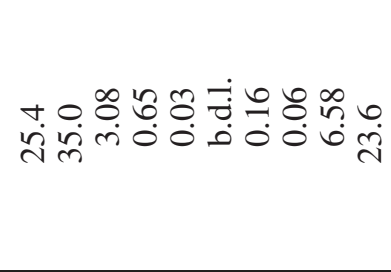 } & \multirow{2}{*}{ Q } & 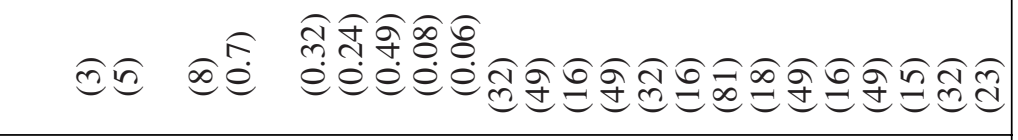 \\
\hline & & & & 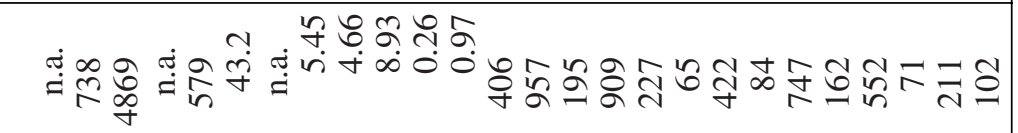 \\
\hline & \multirow{2}{*}{ 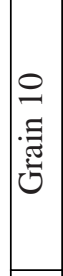 } & \multirow{2}{*}{ 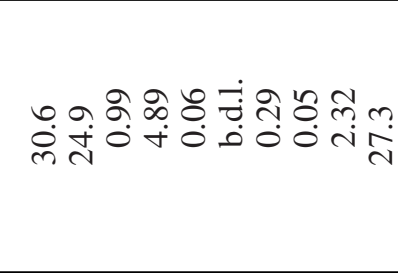 } & \multirow{2}{*}{$\frac{\overrightarrow{\dot{\sigma}}}{\dot{\sigma}}$} & 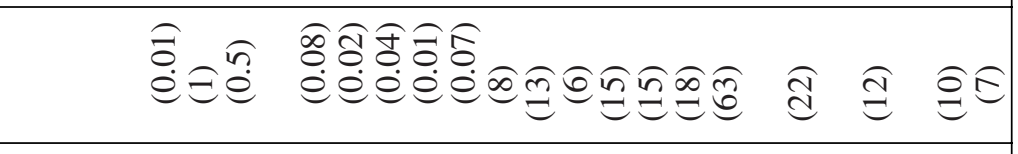 \\
\hline & & & & 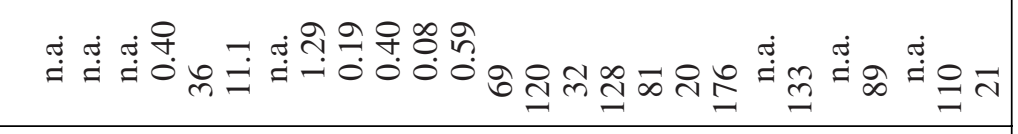 \\
\hline & \multirow{2}{*}{ 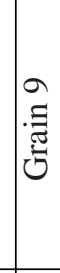 } & \multirow{2}{*}{ 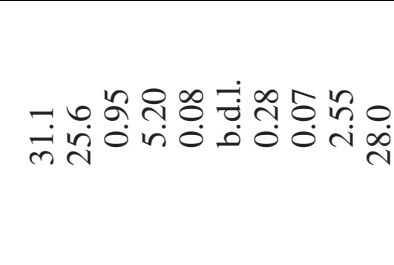 } & \multirow{2}{*}{$\infty$} & 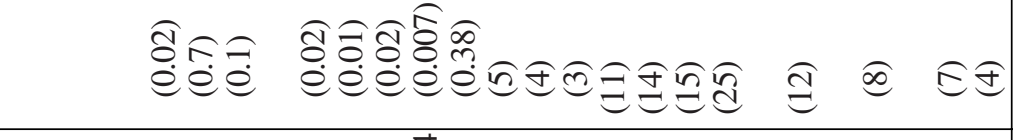 \\
\hline & & & & 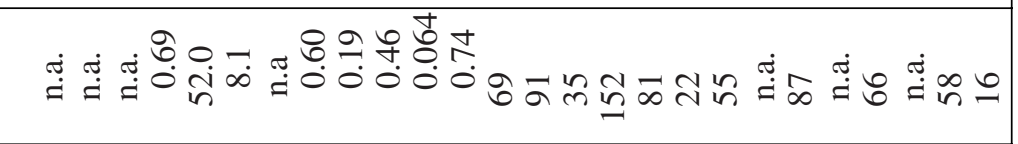 \\
\hline \multirow{2}{*}{ 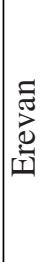 } & \multirow{2}{*}{ 䇊 } & \multirow{2}{*}{ 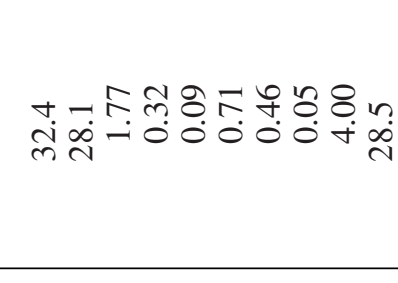 } & \multirow{2}{*}{$\stackrel{t}{\circ}$} & đิ \\
\hline & & & & 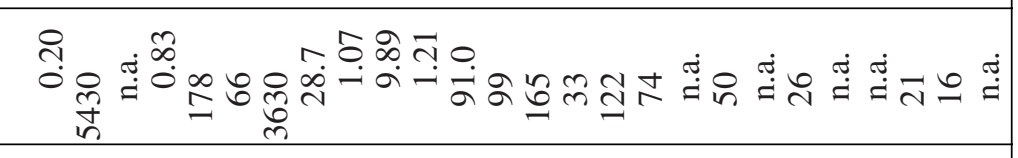 \\
\hline ठี & & 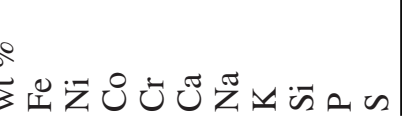 & & 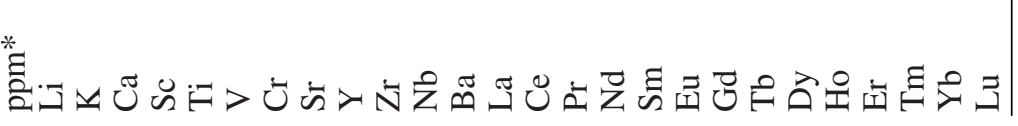 \\
\hline
\end{tabular}


$\mathrm{Sr}$ and then in the sequence $\mathrm{Y}, \mathrm{Zr}, \mathrm{Nb}, \mathrm{Ba}$, whereas the REE contents are very low. Grain 18 from Cold Bokkeveld is similar in trace element patterns to grain $\mathrm{A}$, but is stronger enriched in $\mathrm{Sr}$ rather than in $\mathrm{Ba}$.

(2) Grains 9 and 10 from Cold Bokkeveld show similar lithophile element distribution patterns; their contents are lower than those of CI chondrites (Fig. 10b) and increase slightly with increasing atomic number. There are minor negative anomalies for $\mathrm{Sr}$ (grain 9) and $\mathrm{Ce}$ (grains 9 and 10).

(3) The distribution of lithophile elements in grains 16 and 17 from Cold Bokkeveld (Fig. 10c) is complementary to those of the grains of the first group (Fig. 10a). The contents of these elements are not high and lower or similar to those of CI chondrites; they increase with increasing atomic number from $\mathrm{Ca}$ to $\mathrm{Y}$ and, then, decrease. There is a strong depletion in $\mathrm{Ba}$ and $\mathrm{Sr}$.

Sulfur isotopic systematics was investigated in a grain of P-bearing sulfide from the CM clast of the Erevan howardite (Sahijpal et al., 1995). This grain was also analyzed for trace elements (Table 5). Although no ${ }^{33} \mathrm{~S}$ isotopic anomaly was detected, the obtained $\delta^{36} \mathrm{~S}$ value indicates a possible negative anomaly. However, this value needs to be verified.

\section{DISCUSSION}

\section{Is the P-Bearing Sulfide a Mineral Phase?}

The available data allow us to suggest that the P-bearing sulfide is indeed a mineral phase. This sulfide forms individual grains and aggregates, which occur in a certain textural position, exclusively in a certain type of chondrites, and in association with certain phases (Figs. 1-3). The composition of this sulfide is strictly controlled by the regression line presented above (Fig. 6a). Moreover, there are certain relationships between the chemical compositions of coexisting Pbearing sulfides and phosphides. These observations indicate that the P-bearing sulfide has a stability field, and its composition is controlled by stoichiometry. However, the transmission electron microscopy of several P-bearing sulfide grains (Devouard and Buseck, 1997) showed that these grains probably consist of two unknown phases. Thus, it can be concluded that, if the P-bearing sulfide is not a phase, it could be a phase that underwent breakdown under certain physicochemical parameters.

\section{Chemical Constitution of P-Bearing Sulfides}

Sulfides of $\mathrm{Fe}$ and $\mathrm{Ni}$ containing $\mathrm{P}$ are unknown among synthetic compounds. However, it is well known (e.g., Wells, 1962) that S can substitute for O in $\left(\mathrm{PO}_{4}\right)^{3-}$ groups, resulting in the formation of P-bearing thio-salts (for instance, $\mathrm{Na}_{3} \mathrm{PS}_{4}$ and $\mathrm{Cu}_{3} \mathrm{PS}_{4}$ ), which can be regarded as P-bearing sulfides. Such natural thiosalts are known for $\mathrm{As}, \mathrm{Sb}$, and $\mathrm{Bi}$, which belong to the same group VI of the Periodic System as P (for instance, tennantite and tetrahedrite). Given the considerable number of phosphorus acids $\left(\mathrm{H}_{3} \mathrm{PO}_{3}, \mathrm{H}_{3} \mathrm{PO}_{2}\right.$, $\mathrm{HPO}_{2}, \mathrm{H}_{4} \mathrm{P}_{2} \mathrm{O}_{5}, \mathrm{H}_{2} \mathrm{PO}_{3}, \mathrm{H}_{3} \mathrm{PO}_{4}, \mathrm{HPO}_{3}$, and $\left.\mathrm{H}_{2} \mathrm{P}_{2} \mathrm{O}_{7}\right)$, it is reasonable to expect the existence of diverse P-bearing thio-acids and thio-salts. Hence, the presence of some $\left[\mathrm{P}_{x}(\mathrm{~S}, \mathrm{O})_{y}\right]$ groups in the structure of $\mathrm{P}$-bearing sulfides can be supposed. However, the stoichiometry of phosphorus acids requires that the $\mathrm{S} / \mathrm{P}$ and $(\mathrm{Fe}+$ $\mathrm{Ni} / \mathrm{P}$ atomic ratios of P-bearing sulfides should be $<4$ and $0.5-1.5$, respectively. This is not the case (Table 3 ), and, consequently, this model of the chemical structure cannot be accepted in general.

The regression line in Fig. 6a allows us to suggest that the P-bearing sulfide could be a solid solution of sulfide and phosphide end members. The intersection of this line with the $x$-axis defines the $(\mathrm{Fe}+\mathrm{Ni}) / \mathrm{P}$ ratio of the phosphide, and the slope of the line yields the $(\mathrm{Fe}+\mathrm{Ni}) / \mathrm{S}$ ratio of the sulfide component. Thus, the composition of the end-members can be expressed as $(\mathrm{Fe}, \mathrm{Ni})_{1.255 \pm 0.036(1 \sigma)} \mathrm{P}$ and $(\mathrm{Fe}, \mathrm{Ni})_{0.965 \pm 0.003(1 \sigma)} \mathrm{S}$. The $\mathrm{Fe} / \mathrm{Ni}$ ratio of the sulfide component (Fig. 6b) must be higher than that of the phosphide component. Minor elements $(\mathrm{Co}, \mathrm{K}$, and $\mathrm{Na})$ may account for $0.02-0.03$ f.u. in the total number of cations. The phosphide component is different from any known natural or synthetic phosphide. Neither barringerite nor schreibersite coexisting with the P-bearing sulfides are appropriate endmembers for such a solid solution. This phosphide component can be defined as a phosphorus analogue of maucherite $\left(\mathrm{Ni}_{11} \mathrm{As}_{8}\right)$ or the synthetic phase $\mathrm{Ni}_{4} \mathrm{As}_{3}$; these phases have tetragonal symmetry. The sulfide end-member is similar in composition to smythite $\left(\mathrm{Fe}_{9} \mathrm{~S}_{11}\right)$, pyrrhotite, or mackinawite. The latter is a tetragonal phase but has a higher Fe/S value compared with the supposed sulfide component.

Thus, to a first approximation, the composition of P-bearing sulfide can be specified by the formula (Fe, $\mathrm{Ni})(\mathrm{S}, \mathrm{P})$, which implies S-P isomorphic substitutions in the structure of this phase. Of course, the solid solution model is a simplification. Phosphide and sulfide need not necessarily be end-members. The solid solution could be based on some intermediate components, for instance, the arsenopyrite-type compound (Fe, $\mathrm{Ni}) \mathrm{PS}$. In addition, the low totals of analyses indicate the presence of light elements in the P-bearing sulfides, most likely $\mathrm{O}$ and/or $\mathrm{H}$. The incorporation of these elements does not change the $\mathrm{S} / \mathrm{P}-(\mathrm{Fe}+\mathrm{Ni}) / \mathrm{P}$ relationships. They may fill some positions in the structure of P-bearing sulfides. For instance, possible end-members are hydrosulfides and hydrophosphides. However, the existence of P-bearing sulfide grains with normal totals (Fig. 5f) suggests that their oxidation and hydration could result from the secondary alteration of a primary $\mathrm{P}$-bearing sulfide free of $\mathrm{O}$ and $\mathrm{H}$.

The presence of $\mathrm{Cr}$ and $\mathrm{Ca}$ introduces additional complexity. As was noted above, the compositions of $\mathrm{Cr}$ - and $\mathrm{Ca}$-rich $\mathrm{P}$-bearing sulfides fall on the general 
regression line (Fig. 6a). Therefore, such sulfides could have the compositions $(\mathrm{Fe}, \mathrm{Ni})_{1-x} \mathrm{Cr}_{x}(\mathrm{~S}, \mathrm{P})_{1-x}$ and $(\mathrm{Fe}, \mathrm{Ni})_{1-x} \mathrm{Ca}_{x}(\mathrm{~S}, \mathrm{P})_{1-x}$. In such a case, the incorporation of $\mathrm{Cr}$ and $\mathrm{Ca}$ does not affect the $\mathrm{S} / \mathrm{P}-(\mathrm{Fe}+\mathrm{Ni}) / \mathrm{P}$ relationships. However, $\mathrm{Cr}$ - and $\mathrm{Ca}$-rich sulfides usually show low analytical totals, which are negatively correlated with the contents of these elements (Fig 7). It is obvious that the incorporation of $\mathrm{Cr}$ and $\mathrm{Ca}$ should be coupled with the addition of light elements substituting for $\mathrm{S}$ and $\mathrm{P}$. If this additional component is $\mathrm{O}$ or $\mathrm{OH}$ groups, the general formula of $\mathrm{Cr}$ - and $\mathrm{Ca}$-rich sulfides can be written as $(\mathrm{Fe}, \mathrm{Ni}, \mathrm{Cr}, \mathrm{Ca})(\mathrm{S}, \mathrm{P}, \mathrm{O}, \mathrm{OH})$. Since such sulfides have usually low $\mathrm{S} / \mathrm{P}$ ratios, the light element must substitute mainly for $\mathrm{S}$ rather than $\mathrm{P}$.

Thus, it can be concluded that the chemical constitution of P-bearing sulfides is not fully understood. These sulfides evidently represent a new type of natural phosphorus compounds and are most likely solid solutions with $\mathrm{S}-\mathrm{P}$ isomorphic substitutions. Light elements $(\mathrm{O}$ and $\mathrm{H})$ certainly occur in these sulfides, but are probably related to the processes of secondary alteration.

\section{Formation Conditions}

There is no evidence that the P-bearing sulfides crystallized from a melt. They are absent in the objects that are undoubtedly chondrules. No traces of melt were found in the aggregates hosting P-bearing sulfides. Consequently, P-bearing sulfides likely were not produced by melt crystallization.

It is also improbable that the formation of P-bearing sulfides was related to secondary alteration in the CM chondrite parent body. Phyllosilicates and tochilinite that were supposedly produced by such processes replace these sulfides and fill fractures cutting P-bearing sulfide grains. On the other hand, P-bearing sulfides are absent in veins cutting CM chondrites and filled with the products of hydrothermal alteration. This suggests that P-bearing sulfides existed before the occurrence of secondary alteration. Moreover, forsterite, pyroxenes, diopside, daubreelite, eskolaite, and phosphides, which systematically associate with P-bearing sulfides, are high-temperature phases rather than products of hydrothermal alteration. It is noteworthy that daubreelite, phosphides, and eskolaite are very rare phases, and, consequently, their association with P-bearing sulfides cannot be accidental. In addition, the compositions of phosphides and P-bearing sulfides are interrelated (Fig. 9d), which indicates their cognate relationships. Therefore, it can be supposed that the P-bearing sulfides were formed in the course of nebular processes, similar to other high-temperature components of $\mathrm{CM}$ chondrites. The processes of secondary alteration on the CM chondrite parent body could be responsible for the oxidation and hydration of P-bearing sulfides, but this could also occur under nebular conditions.
Phosphorus-bearing sulfides were never found in $\mathrm{Ca}-\mathrm{Al}$-rich inclusions (CAIs) in association with $\mathrm{Fe}-$ Ni metal and normal sulfides, except for a single case of the Boriskino meteorite (Fig. 3d). On the other hand, P-bearing sulfides associate with diopside, which is the last condensate phase in the CAIs assemblage, and forsterite-pyroxene aggregates, whose formation preceded the condensation of $\mathrm{Fe}-\mathrm{Ni}$ metal in the solar nebula at a total pressure of $<\sim 10^{-4}$ atm (Grossman, 1972). This implies that P-bearing sulfides were stable in the solar nebula after the formation of CAIs but had to react with gas during the condensation of $\mathrm{Fe}-\mathrm{Ni}$ metal. It is important that there are no reaction relationships between coexisting P-bearing sulfides and phosphides, which suggests that the sulfides could not be produced from phosphides by sulfidization. On the other hand, the absence of associations of P-bearing sulfides with metal does not support the suggestion of Lauretta et al. (1997) on their formation by the sulfidization of metal. Moreover, this suggestion is inconsistent with the presence of lithophile elements in the P-bearing sulfides. Although the experimental products of metal sulfidization are enriched in P and S (Lauretta et al., 1997, 1998), their chemical composition is different from that of the P-bearing sulfides. Thus, it should be concluded that the P-bearing sulfides could not be produced by metal-gas or phosphide-gas reactions and are probably primary products of condensation in the solar nebula or products of a reaction between an unknown phase and solar gas.

The most common assemblage of P-bearing sulfide + phosphides + eskolaite + daubreelite provides some constraints on the conditions of its formation. Model calculations (e.g., Petaev and Lavrukhina, 1986) suggest that $\mathrm{CrS}$ condenses from a gas of solar composition (but at $\mathrm{C} / \mathrm{O}=1$ ) and reacts at $1180 \mathrm{~K}$ with the gas to form eskolaite rather than daubreelite. However, eskolaite and daubreelite can be in equilibrium at temperatures of less than $1280 \mathrm{~K}$ at a sulfur fugacity corresponding to the $\mathrm{Fe}-\mathrm{FeS}$ buffer. The corresponding oxygen fugacity values are very low and characteristic of enstatite chondrites (Petaev and Lavrukhina, 1986). The occurrence of phosphides rather than phosphates in association with P-bearing sulfides and high potassium contents in these sulfides are consistent with these estimates. Consequently, the P-bearing sulfides were probably formed under reducing conditions similar to the formation conditions of enstatite chondrites.

Phosphorus-bearing sulfides must not be stable during thermal metamorphism in the parent body. They are absent in petrologic type 3 chondrites and, consequently, must disappear at metamorphic temperatures of $400-600^{\circ} \mathrm{C}$, which are supposed for such chondrites (e.g., Dodd, 1981). On the other hand, the absence of P-bearing sulfides in the Dhofar 225 chondrite, which is probably a metamorphosed CM chondrite (Ivanova et al., 2002), may indicate that these sulfides are unstable already above $245^{\circ} \mathrm{C}$ (temperature of tochilinite decomposition). Owing to thermal metamorphism, the 
P-bearing sulfides could transform into the Ca phosphate + troilite + pentlandite + metal assemblage, which is characteristic of many chondrites (e.g., Rambaldi and Wasson, 1981; Murrell and Burnett, 1983; Rubin and Grossman, 1985).

\section{Phosphorus-Bearing Sulfides and the Lithology of CM Chondrites}

Additional constraints on the formation of P-rich opaque minerals can be obtained from the lithologic composition of CM chondrites. In the Murchison, Murray, EET96016, GRA 98074, Banten, LEW 85311, EET 96029, QUE 97077, and MAC 88100 meteorites, which contain numerous high-temperature forsteritepyroxene aggregates, P-bearing sulfides show the lowest $\mathrm{S} / \mathrm{P}$ and $\mathrm{Fe} / \mathrm{Ni}$ ratios and are accompanied by schreibersite with high $\mathrm{Fe} / \mathrm{Ni}$ ratios (Tables 1, 2; Figs. 8, 9d). These sulfides are usually rich in $\mathrm{Cr}$ and show limited compositional variations. In contrast, sulfides with high $\mathrm{S} / \mathrm{P}$ and $\mathrm{Fe} / \mathrm{Ni}$ values associate mainly with low-Fe/Ni barringerite and are most abundant in the ALH 83100, ALH 83102, ALH 84029, and Y-82042 chondrites, which are dominated by the matrix material. Other $\mathrm{CM}$ chondrites with moderate matrix contents contain P-bearing sulfides of intermediate or very diverse compositions associating usually with both phosphides, although barringerite is the dominant phase showing a lower $\mathrm{Fe} / \mathrm{Ni}$ value compared with schreibersite (Fig. 9d). Variations in the content of matrix material in $\mathrm{CM}$ chondrites correlate with the degree of chondrule alteration and bulk contents of $\mathrm{Na}$ and ${ }^{36} \mathrm{Ar}$ (McSween, 1979; Schultz and Kruse, 1989; Browning et al., 1996). It was suggested that some of these parameters are indicators of hydrothermal alteration under the conditions of the CM chondrite parent body (Browning et al., 1996). However, the correlation between the chemical compositions of P-bearing sulfides and phosphides, on the one hand, and the abundance of matrix material, on the other hand, suggests that the indexes of secondary alteration reflect probably the conditions of accretion rather than hydrothermal alteration in the parent body. These alterations were probably minor in CM meteorites, because these processes would have resulted in the complete replacement of very small grains of P-bearing sulfides and phosphides with secondary phases. Thus, it can be supposed that the CM chondrites of the Murchison type with high contents of forsterite-pyroxene aggregates are products of accretion of materials enriched in high-temperature condensates, whereas the CM chondrites of the ALH 83100 type with high contents of matrix material were formed mainly from low temperature condensates. Other CM chondrites contain either condensation products of intermediate temperatures or mixtures of various condensates. If this is true, high-Fe/Ni schreibersite and P-bearing sulfide with low $\mathrm{Fe} / \mathrm{Ni}$ and $\mathrm{S} / \mathrm{P}$ ratios and high $\mathrm{Cr}$ content, which are typical of Murchison-type chondrites, must be stable in the solar nebula at high temperatures. In contrast, low-Fe/Ni barringerite and $\mathrm{P}$-bearing sulfide with high $\mathrm{Fe} / \mathrm{Ni}$ and $\mathrm{S} / \mathrm{P}$ ratios, which are typical of the CM chondrites of the ALH 83100 type, must be stable at low temperatures. The $\mathrm{Fe} / \mathrm{Ni}$ ratio of phosphides must decrease and the $\mathrm{Fe} / \mathrm{Ni}$ and $\mathrm{S} / \mathrm{P}$ ratios of $\mathrm{P}$-bearing sulfides must increase with decreasing condensation temperature in the solar nebula (Fig. 9d).

\section{Evidence for the Presence of a Presolar Component}

It is probable that P-bearing sulfides were formed in the nebula under reducing conditions. Lodders and Fegley (1995) theoretically calculated the condensation sequence under such conditions, i.e., at high $\mathrm{C} / \mathrm{O}$ ratios, with application for the modeling of the elemental composition of extrasolar $\mathrm{SiC}$ grains (Amari et al., 1995). It was shown that $\mathrm{Ti}, \mathrm{Nb}, \mathrm{Zr}$, and $\mathrm{V}$ carbides must condense first, followed by $\mathrm{SiC}$ and, subsequently, Y, Sc, $\mathrm{REE}, \mathrm{Ca}, \mathrm{Ba}$, and $\mathrm{Sr}$ sulfides. It is also assumed that $\mathrm{Y}$ and REEs can be in part incorporated in refractory carbides. Iron carbides appear in the gas after the formation of $\mathrm{SiC}$ but before sulfide condensation. There are no thermodynamic data for P-bearing sulfides, and those for phosphides are very fragmentary. It can be supposed that P-bearing sulfides could condense together with $\mathrm{Fe}$ carbides or form by the reaction of these carbides with gas. In any case, the distribution of trace elements in P-bearing sulfides must be controlled by the initial abundances of elements in the parent gas, partition coefficients of elements between crystals and gas, and fractionation of crystals. As a first approximation, the partition coefficients of all refractory elements can be assumed identical, especially for the elements of the same valence (e.g., Ti and $\mathrm{Zr} ; \mathrm{Y}$ and $\mathrm{Sc} ; \mathrm{Ca}, \mathrm{Sr}$, and $\mathrm{Ba}$ ). In such a case, the ratios of elements of similar volatility (e.g., $\mathrm{Zr} / \mathrm{Ti}$, $\mathrm{Y} / \mathrm{Sc}, \mathrm{Ba} / \mathrm{Ca}$, and $\mathrm{Sr} / \mathrm{Ca}$ ) must reflect element ratios in the initial gas, and the ratios of elements of different volatility (e.g., $\mathrm{Zr} / \mathrm{Ba}$ and $\mathrm{Ti} / \mathrm{Ca}$ ) must be controlled by both the initial ratios and crystal fractionation from the gas phase. It is important to emphasize that some of these elements (for instance, Ti, $\mathrm{Zr}$, and $\mathrm{Nb}$ or $\mathrm{Ca}$ and $\mathrm{Sr}$ ) do not fractionate significantly in geochemical processes, and their initial ratios cannot be significantly affected by secondary processes.

Grain A from the Cold Bokkeveld meteorite and grains from Nogoya and Erevan have very high $\mathrm{Sr} / \mathrm{Ca}$, $\mathrm{Ba} / \mathrm{Ca}, \mathrm{Zr} / \mathrm{Ti}$, and $\mathrm{Y} / \mathrm{Sc}$ values compared with $\mathrm{CI}$ chondrites (Fig. 10a). This indicates that they condensed from a gas of nonsolar composition enriched in $\mathrm{Sr}, \mathrm{Ba}$, $\mathrm{Zr}$, and Y; i.e., elements formed in the $s$-process (slow neutron capture). However, the low $\mathrm{Zr} / \mathrm{Ba}$ and $\mathrm{Nb} / \mathrm{Sr}$ ratios suggest that the high-temperature condensates of $\mathrm{Ti}, \mathrm{Zr}$, and other elements were eliminated from the gas before the formation of these grains. According to the model calculations of Lodders and Fegley (1995), such element distribution is characteristic of the $\mathrm{SiC}$ grains that condensed from a gas strongly enriched in $s$-pro- 
cess elements after the removal of refractory condensates (Fig. 10a). It was supposed (Lodders and Fegley, 1995) that N-type carbon stars could be the source of such SiC grains. Grain 18 from Cold Bokkeveld has a positive Sr (but not Ba) anomaly (Fig. 10a) and could also condense from a gas enriched in $s$-process elements.

Grains 9 and 10 from Cold Bokkeveld (Fig. 10b) are not significantly enriched in $s$-process elements. The abundances of these elements compared with other elements of similar volatility are higher by a factor of only $3-4$. The heavy elements (compared with light ones) of the $s$-process are probably more abundant relative to the solar concentrations, and there is no evidence for element fractionation with respect to volatility. According to the model calculations of Lodders and Fegley (1995), a similar distribution is characteristic of the $\mathrm{SiC}$ grains that condense from a gas variably enriched in $s$ process elements. The formation of such $\mathrm{SiC}$ grains could be related to $\mathrm{CH}$-type carbon stars (Lodders and Fegley, 1995).

Grains 16 and 17 from Cold Bokkeveld (Fig. 10c) are also weakly enriched in the refractory elements of the $s$-process, and their contents are only 2-3 times higher than those of other refractory elements. This is indicated by elevated $\mathrm{Zr} / \mathrm{Ti}$ and $\mathrm{Y} / \mathrm{Sc}$ ratios. The strong depletion in $\mathrm{Ba}$ and $\mathrm{Sr}$ shows that these grains were separated from the initial gas before the condensation of volatile elements. A similar element distribution (Fig. 10c) is characteristic of $\mathrm{SiC}$ grains that condensed in a gas enriched in $s$-process elements by a factor of three but at higher temperature (Lodders and Fegley, 1995). A possible source of such grains is also $\mathrm{CH}$-type carbon stars (Lodders and Fegley, 1995).

Thus, the trace element compositions of P-bearing sulfides show evidence for element fractionation with respect to volatility, which is typical of the condensation of phases under reducing conditions. In addition, these sulfides are enriched in $s$-process elements and, consequently, could be of extrasolar origin or at least inherit traces of extrasolar nucleosynthesis processes from a precursory phase. The former suggestion seems to be less probable for the following reasons. The anomalies in the contents of $s$-process elements imply that the formation of P-bearing sulfides was related to the evolution of carbon stars. In such a case, the isotopic composition of $\mathrm{S}$ has to be considerably enriched (by a factor of 2-3) in ${ }^{36} \mathrm{~S}$ (Gallino et al., 1990), but the P-bearing sulfide grain from the CM clast of Erevan shows no such enrichment (Sahijpal et al., 1995). Therefore, it is more probable that the P-bearing sulfides were produced by the sulfidization of a precursor phase of extrasolar origin (probably, Fe-Ni carbide) in the solar nebula. It is important that P-bearing sulfides from different aggregates show different trace-element distribution patterns. This may indicate that their precursors were formed in different carbon stars, under different conditions, or at different stages of the evolution of stellar atmospheres.

\section{Phosphorus Distribution in Chondrites}

It was shown that the main carriers of phosphorus in ordinary chondrites are $\mathrm{Ca}$ phosphates, which are believed to be secondary phases formed by the interaction of $\mathrm{Ca}$ silicates with P-bearing $\mathrm{Fe}-\mathrm{Ni}$ metal during thermal metamorphism (e.g., Murrell and Burnett, 1983; Goreva and Burnett, 2001). It is suggested that Pbearing $\mathrm{Fe}-\mathrm{Ni}$ metal and schreibersite are primary phases that condensed from the solar gas (Grossman and Olsen, 1974; Wai and Wasson, 1977; Fegley and Lewis, 1980). However, our study showed that P-bearing sulfides and barringerite were possibly also primary phases, which could be transformed to phosphate-sulfide assemblages during thermal metamorphism. A strong tendency of Ca phosphates to associate with troilite in ordinary chondrites was noted previously (e.g., Kurat and Kurzweil, 1965; Murrell and Burnett, 1983) and suggests the possibility of the chalcophile behavior of $\mathrm{P}$. The total abundance of $\mathrm{P}$ in $\mathrm{CM}$ chondrites $(0.09 \mathrm{wt} \%)$ is equivalent to the presence of $2 \mathrm{wt} \%$ P-bearing sulfides or $0.4 \mathrm{wt} \%$ barringerite. Our estimates for the contents of these phases in CM chondrites are significantly lower (Table 1). As was noted above, these values can be underestimated owing to the unknown abundance of small grains $(<5 \mu \mathrm{m}$ in size $)$ and the degree of their degradation during secondary alteration. However, it would be premature to state that P-bearing sulfides and phosphides are the main primary hosts of phosphorus in CM meteorites.

\section{CONCLUSIONS}

The P-bearing Fe-Ni sulfide is a phase (or a former phase) showing certain chemical characteristics and occurring in certain assemblages; consequently, it should have its thermodynamic stability field. This sulfide represents a new type of phosphorus compounds, most likely a solid solution with S-P isomorphic substitutions. The characteristic minor elements of P-bearing sulfides are $\mathrm{Cr}, \mathrm{Ca}, \mathrm{Co}, \mathrm{K}$, and $\mathrm{Na}$. The presence of light elements $(\mathrm{O}$ and $\mathrm{H})$ can be related to secondary alteration.

Up to now, P-bearing sulfides have been found only as accessory phases in CM chondrites, which show different abundances and compositions of P-bearing opaque phases. These differences in the group of CM chondrites reflect probably the conditions of agglomeration of material condensed from the gas of the solar nebula.

Barringerite, schreibersite, eskolaite, and daubreelite are the most common phases coexisting with these sulfides. There is a negative correlation between the Fe/Ni values of coexisting P-bearing sulfides and phosphides; $\mathrm{Fe}-\mathrm{Ni}$ metal has never been observed in association with P-bearing sulfides. 
The P-bearing sulfide is a primary phase formed in nebular processes rather than a product of secondary alteration under the conditions of the $\mathrm{CM}$ chondrite parent body. This phase is stable in the solar nebula after the formation of CAIs and before the condensation of $\mathrm{Fe}-\mathrm{Ni}$ metal. Under high temperatures, the Pbearing sulfide enriched in $\mathrm{Cr}$ and showing low $\mathrm{Fe} / \mathrm{Ni}$ and $\mathrm{S} / \mathrm{P}$ ratios coexists with schreibersite. As temperature decreases, schreibersite is replaced by barringerite. This is accompanied by a decrease in the Fe/Ni ratio of phosphides and an increase in the Fe/Ni and $\mathrm{S} / \mathrm{P}$ ratios of coexisting P-bearing sulfides.

Trace element data allow us to suggest that the P-bearing sulfides retained traces of extrasolar nucleosynthesis processes related to different types of carbon stars. The P-bearing sulfides were most likely formed within the solar nebula owing to the sulfidization of an extrasolar precursor phase, probably $\mathrm{Fe}-\mathrm{Ni}$ carbide.

Phosphorus-bearing sulfides are unstable during thermal metamorphism under parent body conditions and are probably transformed into phosphate-sulfide assemblages, which are widespread in chondrites.

\section{ACKNOWLEDGMENTS}

This study was financially supported by the Russian Foundation for Basic Research, project no. 03-0520008; Program no. 18 of the Presidium of the Russian Academy of Sciences; the Austrian Science Fund (FWF); and the Austrian Academy of Sciences.

\section{REFERENCES}

1. S. Amari, P. Hoppe, E. Zinner, and R. S. Lewis, "TraceElement Concentrations in Single Circumstellar Silicon Carbide Grains from the Murchison Meteorite," Meteorit. Planet. Sci 30, 679-693 (1995).

2. E. Anders and N. Grevesse, "Abundances of the Elements: Meteoritic and Solar," Geochim. Cosmochim. Acta 53, 197-214 (1989).

3. A. Bischoff and T. Geiger, "The Unique Carbonaceous Chondrite Acfer 094: The First CM3 Chondrite(?)," Proc. 25th Lunar Planet. Sci. Conf., 115-116 (1994).

4. N. Z. Boctor, G. Kurat, C. M. O. D. Alexander, and C. T. Prewitt, "Sulfide Mineral Assemblages in Boriskino CM Chondrite," Proc. 33th Lunar Planet. Sci. Conf., No. 1534 (2002).

5. F. Brandstätter, M. A. Nazarov, and G. Kurat, "Barringerite from the Santa Catharina Ungrouped Iron Meteorite," Proc. 34th Lunar Planet. Sci. Conf., No. 1681 (2003).

6. A. J. Brearley and R. H. Jones, "Chondritic Meteorites," in Planetary Materials, Ed. by J. J. Papike, (Mineral. Soc. Am., Boulder, 1999), pp. 3-1-3-398 (1999).

7. S. N. Britvin, N. S. Rudashevsky, S. V. Krivovichev, et al., "Allabogdanite, $(\mathrm{Fe}, \mathrm{Ni})_{2} \mathrm{P}$, a New Mineral from the Onello Meteorite, the Occurrence and Crystal Structure," Am. Mineral. 87, 1245-1249 (2002).

8. L. B. Browning, H. Y. McSween, and M. E. Zolensky, "Correlated Alteration Effects in CM Carbonaceous
Chondrites," Geochim. Cosmochim. Acta 60, 26212633 (1996).

9. T. E. Bunch and S. Chang, "Carbonaceous ChondritesII. Carbonaceous Chondrite Phyllosilicates and Light Element Geochemistry as Indicators of Parent Body Processes and Surface Conditions," Geochim. Cosmochim. Acta 44, 1543-1577 (1980).

10. T. E. Bunch and L. H. Fuchs, "A New Mineral: Brezinaite, $\mathrm{Cr}_{3} \mathrm{~S}_{4}$, and the Tucson Meteorite," Am. Mineral. 54, 1509-1518 (1969).

11. T. E. Bunch, S. Chang, U. Frick, et al., "Carbonaceous Chondrites-I. Characterization and Significance of Carbonaceous Chondrite (CM) Xenoliths in the Jodzie Howardite," Geochim. Cosmochim. Acta 43, 1727-1742 (1979).

12. I. Casanova, T. J. McCoy, and K. Keil, "Metal-Rich Meteorites from the Aubrite Parent Body," Proc. 24th Lunar Planet. Sci. Conf., 259-269 (1993).

13. B. Devouard and P. R. Buseck, "Phosphorus-Rich Iron, Nickel Sulfides in CM2 Chondrites: Condensation Or Alteration Products?," Meteorit. Planet. Sci. 32 Suppl., A34 (1997).

14. R. T. Dodd, Meteorites, a Petrologic-Chemical Synthesis (Cambridge University Press, Cambridge, 1981).

15. A. El Goresy, H. Yabuki, K. Ehlers, et al., "Qingzhen and Yamato-691: A Tentative Alphabet for the EH Chondrites," Proc. NIPR Symposium on Antarctic Meteorites, No. 1, 65-101 (1988).

16. B. Fegley and J. S. Lewis, "Volatile Element Chemistry in the Solar Nebula: $\mathrm{Na}, \mathrm{K}, \mathrm{F}, \mathrm{Cl}, \mathrm{Br}$, and P,' Icarus 41, 430-455 (1980).

17. L. H. Fuchs, "Djerfisherite, Alkali Copper-Iron Sulfide: A New Mineral from Enstatite Chondrites," Science 153, 166-167 (1966).

18. R. Gallino, M. Busso, G. Picchio, and C. M. Raiteri, “On the Astrophysical Interpretation of Isotopic Anomalies in Meteoritic SiC Grains," Nature 348, 298-302 (1990).

19. J. S. Goreva and D. S. Burnett, "Phosphate Control on the Thorium/Uranium Variations in Ordinary Chondrites: Improving Solar System Abundances,' Meteorit. Planet. Sci. 36, 63-74 (2001).

20. M. Gounelle, M. E. Zolensky, J.-C. Liou, et al., "Mineralogy of Carbonaceous Chondritic Microclasts in Howardites: Identification of C2 Fossil Micrometeorites," Geochim. Cosmochim. Acta 67, 507-528 (2003).

21. L. Grossman, "Condensation in the Primitive Solar Nebula," Geochim. Cosmochim. Acta 36, 597-619 (1972).

22. L. Grossman and E. Olsen, "Origin of the High Temperature Fraction of C-2 Chondrites," Geochim. Cosmochim. Acta 38, 173-187 (1974).

23. Y. Ikeda, "Petrochemical Study of the Yamato-691 Enstatite Chondrite (E3) IV: Descriptions and Mineral Chemistry of Opaque Nodules," Proc. NIPR Symposium on Antarctic Meteorites, No. 2, 109-146 (1989).

24. M. A. Ivanova, L. A. Taylor, R. N. Clayton, et al., "Dhofar 225 Vs. the CM Clan: Metamorphosed Or New Type of Carbonaceous Chondrite?," Proc. 32nd Lunar Planet. Sci. Conf., No. 1437 (2002).

25. M. Kimura and Y. Ikeda, "Mineralogy and Petrology of an Unusual Belgica 79004 Carbonaceous Chondrite: Genetic Relationships among the Components," Proc. 
NIPR Symposium on Antarctic Meteorites, No. 5, 74119 (1992).

26. G. Kurat and H. Kurzweil, "Der Meteorit von Lanzenkirchen," Ann. Naturhist. Mus. Wien 68, 9-24 (1965).

27. D. S. Lauretta, K. Lodders, and B. Fegley, Jr., "The Formation of Phosphorus-Rich Sulfides by Sulfurization of Meteoritic Metal," Meteorit. Planet. Sci. 32 Suppl., A77 (1997).

28. D. S. Lauretta, K. Lodders, and B. Fegley, Jr., "Kamacite Sulfurization in the Solar Nebula," Meteorit. Planet. Sci. 33, 821-833 (1998).

29. R. A. Lewis, B. Srinivasan, and E. Anders, "Host Phase of a Strange Xenon Component in Allende," Science 190, 1251-1262 (1975).

30. K. Lodders and B. Fegley, Jr., "The Origin of Circumstellar Silicon Carbide Grains Found in Meteorites," Meteorit. Planet. Sci. 30, 661-678 (1995).

31. H. Y. McSween, "Alteration in CM Carbonaceous Chondrites Inferred from Modal and Chemical Variations in Matrix," Geochim. Cosmochim. Acta 43, 1761-1770 (1979).

32. M. T. Murrell and D. S. Burnett, "The Behavior of Actinides, Phosphorus, and Rare Earth Elements during Chondrite Metamorphism," Geochim. Cosmochim. Acta 47, 1999-2014 (1983).

33. M. A. Nazarov, F. Brandstaetter, and G. Kurat, "Carbonaceous Xenoliths from the Erevan Howardite," Proc. 24th Lunar Planet. Sci. Conf., 1053-1054 (1993).

34. M. A. Nazarov, F. Brandstaetter, and G. Kurat, "P-Rich Sulfide, Barringerite, and Other Phases in Carbonaceous Clasts of the Erevan Howardite," Proc. 25th Lunar Planet. Sci. Conf., 979-980 (1994).

35. M. A. Nazarov, F. Brandstaetter, and G. Kurat, "Phosphides and P-Rich Sulphides in the Mighei (CM) Chondrite," Proc. 27th Lunar Planet. Sci. Conf., 939-940 (1996).

36. M. A. Nazarov, F. Brandstaetter, and G. Kurat, "Phosphorian Sulfides and Phosphides in CM Chondrites," Geokhimiya, No. 5, 475-484 (1998) [Geochem. Int. 36, 415-424 (1998)].

37. M. A. Nazarov, F. Brandstaetter, G. Kurat, and T. Ntaflos, "A Calcium Enrichment in Phosphorian Sulfides and
Barringerites from the Cochabamba (CM) Chondrite," Meteorit. Planet. Sci. 35 Suppl., A117 (2000).

38. M. I. Petaev and A. K. Lavrukhina, "On the Genesis of Minerals from Enstatite Meteorites," Meteoritika, No. 45, 49-61 (1986).

39. M. Prinz, M. K. Weisberg, and C. E. Nehru, "LEW88774: A New Type of Cr-Rich Ureilite," Proc. 25th Lunar Planet. Sci. Conf., 1107-1108 (1994).

40. E. R. Rambaldi and J. T. Wasson, "Metal and Associated Phases in Bishunpur, a Highly Unequilibrated Ordinary Chondrite," Geochim. Cosmochim. Acta 45, 1001-1015 (1981).

41. A. E. Rubin and J. N. Grossman, "Phosphate-Sulfide Assemblages and $\mathrm{Al} / \mathrm{Ca}$ Ratios in Type 3 Chondrites," Meteoritics 20, 479-489 (1985).

42. S. Sahijpal, M. A. Nazarov, and J. N. Goswami, "Sulfur Isotopic Studies of a P-Rich Sulfide in a Carbonaceous Xenolith from the Erevan Howardite," Proc. 26th Lunar Planet. Sci. Conf., 1213-1214 (1995).

43. L. Schultz and H. Kruse, "Helium, Neon, and Argon in Meteorites-A Data Compilation," Meteoritics 24, 155-172 (1989).

44. C. M. Wai and J. T. Wasson, "Nebular Condensation of Moderately Volatile Elements and Their Abundances in Ordinary Chondrites," Earth Planet. Sci. Lett. 36, 1-13 (1977).

45. A. Wang, B. L. Jolliff, and L. A. Haskin, "Raman Spectroscopic Characterization of Martian Meteorite Zagami," Proc. 29th Lunar Planet. Sci. Conf., No. 1523 (1998).

46. A. F. Wells, Structural Inorganic Chemistry, 3rd ed. (Oxford Univ. Press, Oxford, 1962).

47. E. Zinner and G. Crozaz, "A Method for the Quantitative Measurement of Rare Earth Elements in the Ion Probe," Int. J. Mass Spectrom. Ion Proc. 69, 17-38 (1986).

48. M. E. Zolensky and A. Ivanov, "The Kaidun Microbreccia Meteorite: A Harvest from the Inner and Outer Asteroid Belt," Chem. Erde 63, 185-246 (2003).

49. M. E. Zolensky, K. Nakamura, M. Gounelle, et al., "Mineralogy of Tagish Lake: An Ungrouped Type 2 Carbonaceous Chondrite," Meteorit. Planet. Sci. 37, 737762 (2002). 